\title{
Tropical Cloud Cluster Environments and Their Importance for Tropical Cyclone Formation
}

\author{
Hsu-Feng TENG \\ Department of Atmospheric Sciences, National Taiwan University, Taipei, Taiwan, and National Center for \\ Atmospheric Research, Boulder, Colorado \\ CHeng-SHANG LeE \\ Department of Atmospheric Sciences, National Taiwan University, Taipei, Taiwan \\ HuANG-HSIUNG Hsu \\ Research Center for Environmental Changes, Academia Sinica, and Department of Atmospheric Sciences, \\ National Taiwan University, Taipei, Taiwan \\ James M. Done AND GReg J. Holland \\ National Center for Atmospheric Research, Boulder, Colorado
}

(Manuscript received 9 October 2018, in final form 13 February 2019)

\begin{abstract}
This study uses a nonhierarchical cluster analysis to identify the major environmental circulation patterns associated with tropical cloud cluster (TCC) formation in the western North Pacific. All TCCs that formed in July-October 1981-2009 are examined based on their 850-hPa wind field around TCC centers. Eight types of environmental circulation patterns are identified. Of these, four are related to monsoon systems (trough, confluence, north of trough, and south of trough), three are related to easterly systems (low-latitude zone, west of subtropical high, and southwest of subtropical high), and one is associated with low-latitude crossequatorial flow. The genesis potential index (GPI) is analyzed to compare how favorable the environmental conditions are for tropical cyclone (TC) formation when TCCs form. Excluding three cluster types with the GPI lower than the climatology of all samples, TCCs formed in monsoon environments have larger sizes, lower brightness temperatures, longer lifetimes, and higher GPIs than those of TCCs formed in easterly environments. However, for TCCs formed in easterly environments, the average GPI for those TCCs that later develop into TCs (developing TCCs) is higher than that for other TCCs (nondeveloping TCCs). This difference is nonsignificant for TCCs formed in monsoon environments. Conversely, the average magnitudes of GPI are similar for developing TCCs, regardless of whether TCCs form in easterly or monsoon environments. In summary, the probability of a TCC to develop into a TC is more sensitive to the environmental conditions for TCCs formed in easterly environments than those formed in monsoon environments.
\end{abstract}

\section{Introduction}

Tropical cloud clusters (TCCs) are the precursors of tropical cyclones (TCs), and in favorable environments can develop into TCs (McBride 1981; McBride and Zehr 1981; Williams and Houze 1987; Lee 1989; Mapes and Houze 1993; Gray 1998; Bessho et al. 2010). Several studies (Leary and Houze 1976, 1979; Wang et al. 2007; Kerns and Chen 2015) have analyzed the structure and

Corresponding author: Cheng-Shang Lee, cslee@ntu.edu.tw evolution of selected TCCs during specific experiments, but no previous study analyzed the important characteristics for TCCs over a long time period. Previous studies indicated that the formation of TCCs, in the western North Pacific (WNP), is related to large-scale circulations, including the monsoon trough, monsoon confluence zone, and intertropical convergence zone (ITCZ; Hennon et al. 2011, 2013; Kerns and Chen 2013; Teng 2016). In addition, TCC formation is more sensitive to environmental conditions than TC formation (Teng et al. 2014). 
When the circulation of the WNP is affected by largescale oscillations, such as the Madden-Julian oscillation (Chen et al. 2018; Zhao et al. 2018) and El NiñoSouthern Oscillation (ENSO; Hennon et al. 2013; Teng et al. 2014), the numbers of TCC and TC formations are also influenced. ENSO is the most significant interannual signal associated with large-scale air-sea interactions in the Pacific (Trenberth 1997). Teng et al. (2014) showed that the numbers of TCCs formed in the western part of the WNP and eastern part of the WNP, which are separated by $140^{\circ} \mathrm{E}$, correlate significantly with the oceanic Niño index (ONI), and their coefficients are of opposite sign. However, the number of TCCs in the entire WNP is not altered by ENSO. This phenomenon is similar to the ENSO modulation on TC formation shown in previous studies, caused by the compensation effects between the western and eastern WNP (Chan 2000; Wang and Chan 2002). Even though the patterns of the monsoon system and subtropical high are altered by ENSO events, the total number of TCCs in the WNP is not significantly altered (Hennon et al. 2013; Teng et al. 2014). In other words, different circulation patterns can generate TCCs and affect their distributions in the WNP.

Although ENSO does not affect the number of TCCs formed in the entire WNP, the characteristics of TCCs may change under different circulation patterns caused by ENSO, which have not been discussed in previous studies. To avoid smoothing the critical features, TCCs that form in different environments must be discussed separately. Therefore, this study uses a cluster analysis method to classify the major environmental circulation patterns associated with TCC formations in the WNP during a 29-yr period (1981-2009). The important characteristics for TCC formation in each circulation pattern are analyzed.

Cluster analysis is a specific statistical method of classification that can objectively categorize original data into a few clusters, thereby reducing the variance in each cluster and emphasizing the difference among clusters. Cluster analysis is used to process the classification when the number of groups is not known and in the absence of any hypothesis (Everitt et al. 2011; Garson 2014). In previous studies, cluster analysis has been applied to analyze circulation and TCs (Harr and Elsberry 1995a,b), major TC trajectory types (Harr and Elsberry 1991; Camargo et al. 2004, 2007c; Kim et al. 2011), the ENSO impacts on TC (Camargo et al. 2007d; Kim and Seo 2016), and TC rainfall and landfall (Choi et al. 2012; Ramsay et al. 2012; Murakami et al. 2016). Although the groups classified by cluster analysis are not orthogonal to each other, cluster analysis can determine major circulation patterns that are closer to the actual circulation, and aids interpretation of the physical mechanisms of
TCC formation. Therefore, cluster analysis is utilized as the classifying methodology in this study.

The large-scale and synoptic environments only affect the probability of an initial disturbance to develop into a $\mathrm{TC}$, rather than directly determine the process of TC formation (Ooyama 1982; Lin and Lee 2011; Hsieh et al. 2017). However, whether this is true for all large-scale environment types is unknown. Therefore, the sensitivity of whether a TCC can develop into a TC under different environmental circulation patterns must be analyzed. In this study, cluster analysis is used to analyze 29-yr datasets to identify the major types of environmental circulation patterns associated with TCC formation in the WNP. Additionally, patterns identified as clusters may be compared to determine statistical characteristics of each cluster type as they relate to TCC formation. Then, the importance of the environmental conditions of TCC formation under different circulation patterns for the probability of a TCC to develop into a TC will be explored. The objective settings of the cluster analysis are described in section 2 . The characteristics of TCCs that form in different environments and their interannual variability are analyzed in section 3. The environmental conditions of each cluster type and their importance to TC formation are compared in section 4. Finally, the discussions and conclusions are presented in section 5 .

\section{Data and methodology}

\section{a. Data and definitions}

Five datasets are used in this study. First, the TCC dataset constructed by Teng et al. (2014) is used. They tracked TCCs in the WNP during July-October 1981-2009 based on objective criteria using Gridded Satellite (GridSat v01r01) data (Knapp 2008; Knapp et al. 2011). GridSat is a homogeneous, $0.07^{\circ} \times 0.07^{\circ}$, 3-hourly, and near-global $\left(70^{\circ} \mathrm{S}-70^{\circ} \mathrm{N}, 180^{\circ}-180^{\circ}\right)$ cloud-top brightness temperature $\left(T_{b}\right)$ dataset. A potential TCC candidate must have a high cloud and cold $T_{b}\left(T_{b}\right.$ lower than $\left.235 \mathrm{~K}\right)$ spread over a certain area $\left(10^{\circ} \mathrm{S}-40^{\circ} \mathrm{N}, 90^{\circ} \mathrm{E}-170^{\circ} \mathrm{W}\right)$ and with at least one embedded mesoscale convective system (MCS, $T_{b}$ lower than $208 \mathrm{~K}$ ). The size of the outer convection area and the MCS must be larger than 89419 and $6776 \mathrm{~km}^{2}$ (the third quartile for all potential TCC candidates), respectively. When tracking a TCC, either the motion of the TCC candidate between two successive time periods ( $3 \mathrm{~h})$ must be less than $450 \mathrm{~km}$ or the overlapping area of the TCC at two successive time periods must exceed $50 \%$ of the TCC area at either of these time periods. A total of 16078 potential candidates are identified, and 2248 of them persist for more than $24 \mathrm{~h}$ and are defined as TCCs. The first time when the TCC is identified is recorded as the 


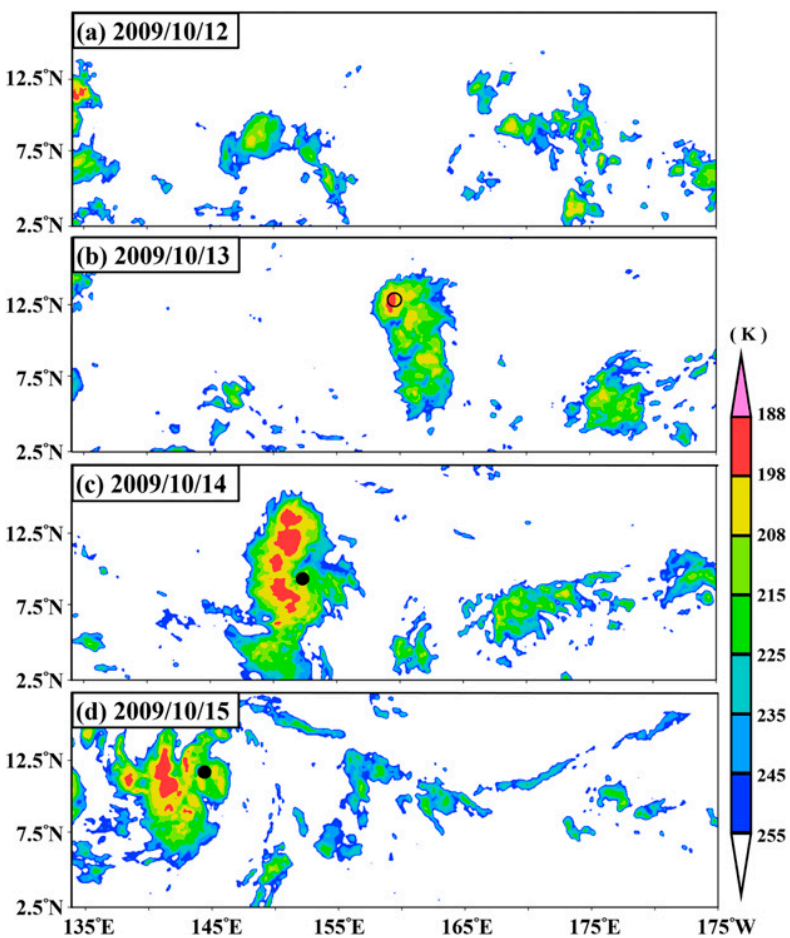

FIG. 1. GridSat $T_{b}$ at 0000 UTC 12-15 Oct 2009, showing the development of a sample TCC into TC. The open circle represents the center of the TCC, and the dot shows the center of the TC, which later became Typhoon Lupit (2009), based on JTWC best track data.

time of TCC formation. The center of a TCC is taken as the geometric center of the largest MCS embedded in the TCC. The sizes of TCC and MCS for each time period are recorded. Since stricter criteria of structure and size are used to select TCCs, the TCCs analyzed in this study have a higher probability to develop further than those analyzed in previous studies (Lee 1989; Mapes and Houze 1993; Bessho et al. 2010; Hennon et al. 2011, 2013). Figure 1 shows the formation of an example TCC and its development into a TC.

Second, the best track data of the Joint Typhoon Warning Center (JTWC) are used in this study. A tropical disturbance is defined as a TC when its maximum sustained surface wind speed equals or exceeds $25 \mathrm{kt}\left(\approx 13 \mathrm{~m} \mathrm{~s}^{-1}\right)$. If a TCC is located within $450 \mathrm{~km}$ from the TC center or the center of a TC is located in the TCC convection area, it is defined as the development of a TCC into a TC. TCCs that develop into TCs are defined as developing TCCs; others, nondeveloping TCCs. In total, there are 531 TCs inside the study domain $\left(0^{\circ}-30^{\circ} \mathrm{N}, 100^{\circ} \mathrm{E}-180^{\circ}\right)$ during the period July-October 1981-2009.

The National Centers for Environmental Prediction (NCEP) Climate Forecast System Reanalysis (CFSR V1) (Saha et al. 2010), a 6-hourly, $0.5^{\circ} \times 0.5^{\circ}$ global gridded dataset with 37 vertical levels, covering 1979-2011 is used to analyze atmospheric parameters. The sea surface temperature used in this study is the Optimum Interpolation Sea Surface Temperature obtained from the National Oceanic and Atmospheric Administration (NOAA), which is a daily and $0.25^{\circ} \times 0.25^{\circ}$ global gridded dataset (Reynolds et al. 2007; Banzon et al. 2016). Finally, the ONI is applied to identify El Niño and La Niña years according to the Climate Prediction Center (CPC) of NOAA. Based on the definition used by the CPC, El Niño years are defined as periods when the $\mathrm{ONI}$ is greater than $+0.5^{\circ} \mathrm{C}$ for at least five consecutive months, including the July-September period. La Niña years are identified with an ONI less than $-0.5^{\circ} \mathrm{C}$. Other periods are considered as neutral years.

\section{b. Cluster analysis settings}

This is the first study in which cluster analysis is applied to objectively analyze the circulation patterns associated with the formation of tropical disturbances over a long period (29yr) using relative coordinates. Cluster analysis with a fixed domain in the WNP has been used in many previous studies (Harr and Elsberry 1991, 1995a,b; Camargo et al. 2004, 2007c,d; Kim and Seo 2016; Murakami et al. 2016). Initially, this study also used the cluster analysis with a fixed domain and continuous time (e.g., Harr and Elsberry 1991, 1995a,b) to identify the major environmental circulation patterns associated with TCC formation. However, results showed that many TCCs that form in different synoptic environments are grouped into the same cluster when the fixeddomain and continuous-time cluster analysis is used (not shown). Therefore, to classify the major environmental circulation patterns associated with TCC formation, the relative coordinates (in space and time) with respect to the TCC formation location must be considered. Data used in the cluster analysis are the $850-\mathrm{hPa}$ wind fields (zonal and meridional winds) over a $40^{\circ} \times 40^{\circ}$ longitude-latitude domain $(81 \times 81$ grid points $)$ centered at the location where a TCC is first identified.

A nonhierarchical cluster analysis, $k$-means clustering (MacQueen 1967), is used to classify the major circulation patterns associated with TCC formation. The $k$-means clustering classifies all samples into $k$ groups using the minimum sum of the squared distance (SSD) from each sample to its centroid within each group and the maximum SSD from each centroid to other centroids, which are defined as:

$$
\begin{gathered}
\min \sum_{i=1}^{k} \sum_{j=1}^{n}\left(x_{j}-\mu_{i}\right)^{2}, \\
\max \frac{1}{2} \sum_{i=1}^{k} \sum_{m=1}^{k}\left(\mu_{m}-\mu_{i}\right)^{2},
\end{gathered}
$$




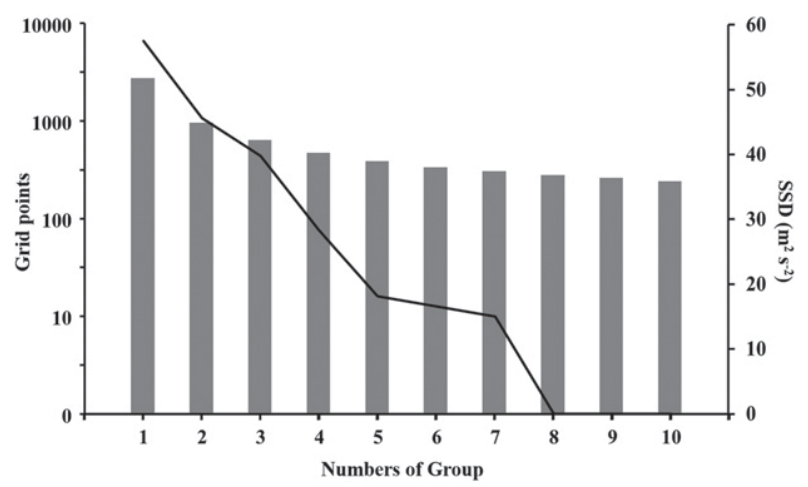

FIG. 2. Number of grid points (black line) that do not pass the ANOVA test at a $95 \%$ confidence level and SSD per grid point (gray bar) for the classifications of different numbers.

where $k$ is the number of groups, $n$ is the number of samples in the $i$ th group, $x_{j}$ is the $j$ th sample in the $i$ th group, and $\mu_{i}\left(\mu_{m}\right)$ is the centroid of samples in the $i$ th ( $m$ th) group. In addition, because the clustering result is sensitive to the initial points of the calculation, the initial points are randomly sampled at the beginning and are gradually converged to the clustering result with smaller SSD by repeating the procedures until a steady solution is obtained.

Acceptable cluster analysis classification requires significant SSDs between groups that must be substantially greater than the SSDs within groups. However, the SSDs decrease continuously when the number of clustering groups is close to the number of total samples, which violates the purpose of the classification. To objectively determine the number of clusters, the SSD for each grid point, each sample, and each group are considered in this study. Because there is no obvious gap in the decreasing trend of SSD associated with increasing cluster number, one-way analysis of variance (ANOVA) is further applied to determine the number of clusters. One-way ANOVA examines the statistical significance of the ratio of the variance between several groups to the variance within each group. The test target of ANOVA is similar to the definition of $k$-means clustering, and is used to assess the classification significance in clustering result (Everitt et al. 2011; Garson 2014). When the result passes the ANOVA, it indicates that at least one group is significantly different from other groups relative to the variance within each group.

In this study, the zonal and meridional winds for every grid point are examined by ANOVA with a 95\% confidence level. In other words, the classifications are affected by the wind direction and wind speed. As shown in Fig. 2, the SSDs decrease continuously when the number of clusters increases. However, when the number of clusters is greater than eight, all grid points pass the ANOVA test with a $95 \%$ confidence level, which indicates that classified wind fields of all grid points are different among groups and are statistically significant. Therefore, an eight-group clustering of the environments associated with TCC formation is presented in this study.

\section{Features of different cluster types}

The number of TCCs that form in each cluster type is shown in Table 1. Note that the labels of the cluster types are arranged in order according to the number of TCCs formed in each cluster type. The general characteristics (i.e., the average circulation, number, location, size, and lifetime) and interannual variability for TCCs formed in each cluster type are explored in this section.

\section{a. General characteristics of each cluster type}

Figure 3 shows the composite of $850-\mathrm{hPa}$ environmental circulation for each cluster type. Results show that the circulation patterns for four cluster types (types

TABLE 1. The corresponding environments and statistics for eight cluster types. The numbers of TCCs formed in each cluster type are shown in the third column. The numbers (percentages, \%) of TCCs that develop into TCs are shown in the fourth column. The average sizes of TCC and MCS $\left(10^{4} \mathrm{~km}^{2}\right)$ at the time of TCC formation are shown in the fifth and sixth columns, respectively. The average lifetimes (h) of nondeveloping TCCs are shown in the last column. Plus signs $(+)$ indicate that the difference between each cluster type and the climatology of all samples for all cluster types passes the $t$ test at a $95 \%$ confidence level.

\begin{tabular}{|c|c|c|c|c|c|c|}
\hline Cluster type & Corresponding environments & TCC & $\mathrm{TC}(\%)$ & TCC size & MCS size & Hours \\
\hline Type 1 & Low-latitude easterly & 403 & $27\left(6.7^{+}\right)$ & $24.2^{+}$ & $2.5^{+}$ & $44.1^{+}$ \\
\hline Type 2 & Monsoon confluence & 370 & $114\left(30.8^{+}\right)$ & 24.4 & 3.0 & $57.0^{+}$ \\
\hline Type 3 & Low-latitude cross-equatorial flow & 299 & $36\left(12.0^{+}\right)$ & $23.7^{+}$ & $2.6^{+}$ & 53.4 \\
\hline Type 4 & Easterly at southwest of subtropical high & 297 & $104\left(35.0^{+}\right)$ & $21.5^{+}$ & 2.7 & 49.3 \\
\hline Type 5 & Monsoon trough & 247 & $71(28.7)$ & $31.2^{+}$ & $3.1^{+}$ & $56.7^{+}$ \\
\hline Type 6 & North of monsoon trough & 227 & $85\left(37.4^{+}\right)$ & 26.1 & $3.6^{+}$ & $57.1^{+}$ \\
\hline Type 7 & Easterly at west of subtropical high & 209 & $56(26.8)$ & 24.1 & 2.9 & 52.5 \\
\hline Type 8 & South of monsoon trough & 196 & $38(19.4)$ & 26.3 & 2.6 & 49.2 \\
\hline Total & & 2248 & $531(23.6)$ & 24.9 & 2.8 & 51.5 \\
\hline
\end{tabular}




\section{(a) Type 1}

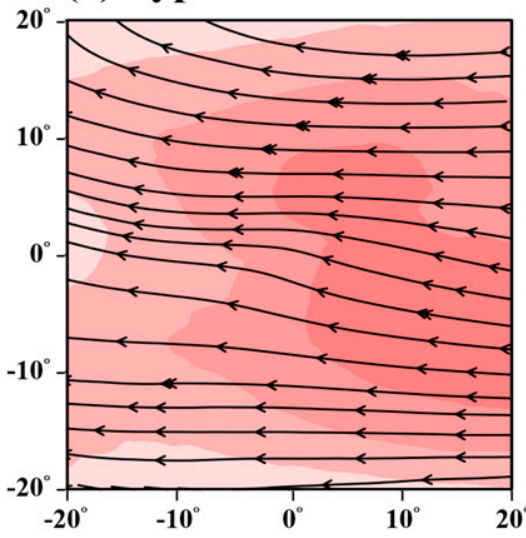

(d) Type 4

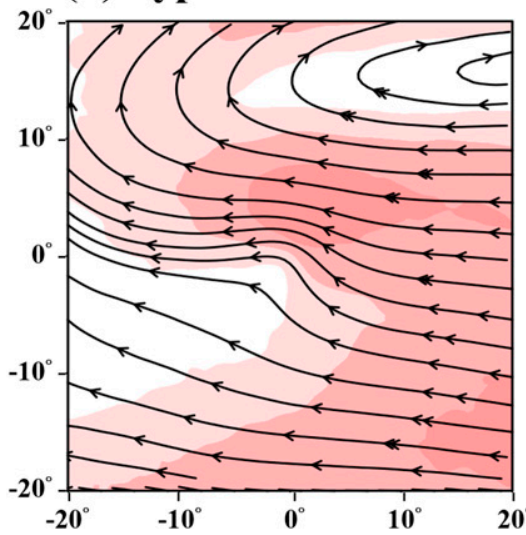

(g) Type 7

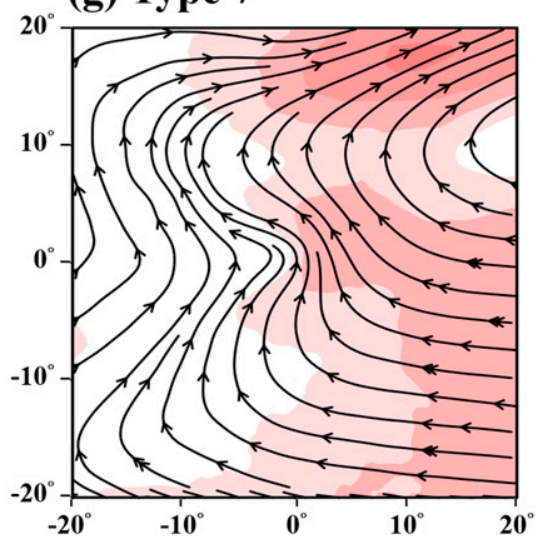

(b) Type 2

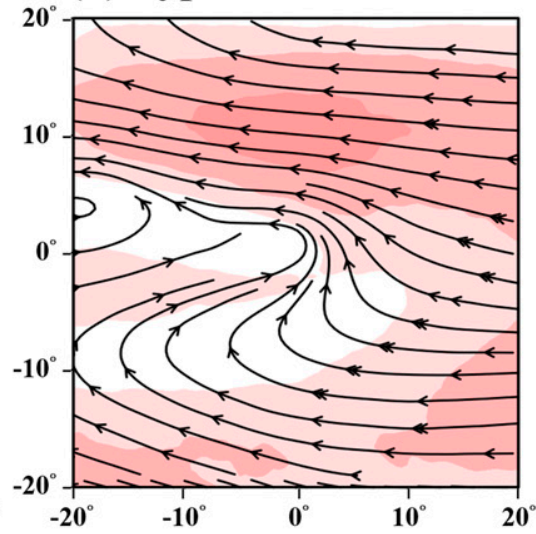

(e) Type 5

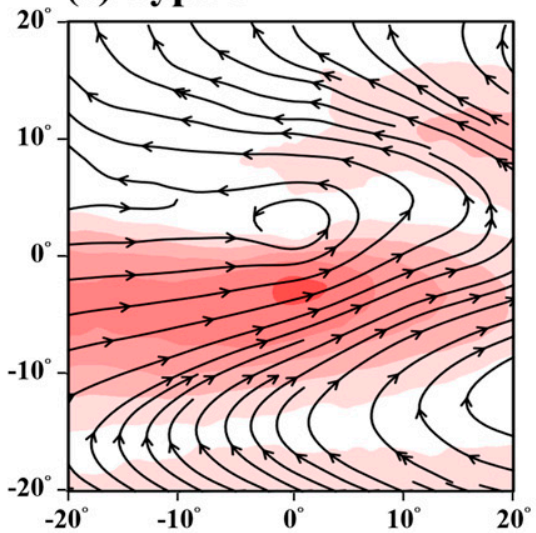

(c) Type 3

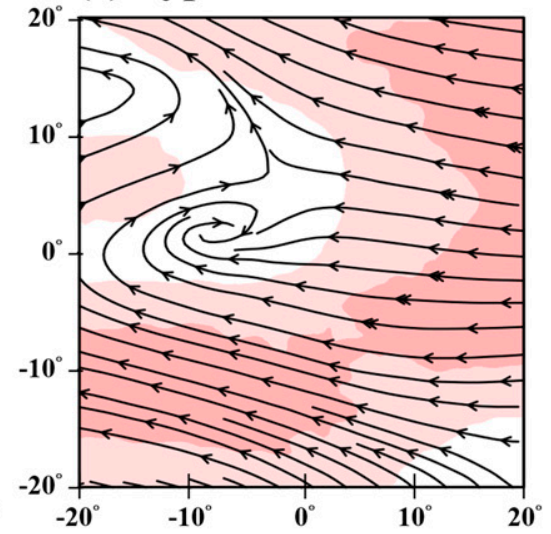

(f) Type 6

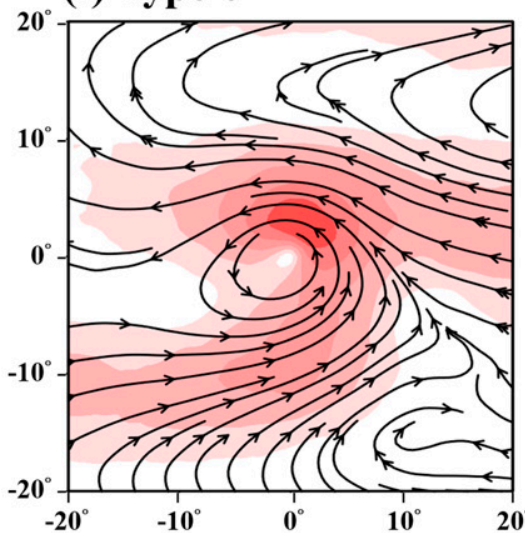

(h) Type 8

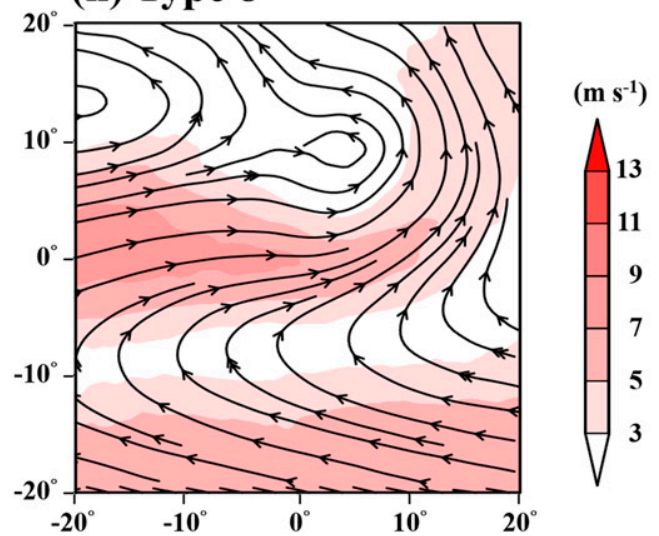

FIG. 3. Composites of 850-hPa streamlines and wind speeds (colored shading) for eight cluster types. The origin in each panel represents the location of TCC formation.

$2,5,6$, and 8) are related to monsoon environments, three (types 1, 4, and 7) are related to easterly environments, and one (type 3) is low-latitude cross-equatorial flow environment. The circulations with a large-scale difference of zonal wind between the easterly at the north side and the westerly at the south side (i.e., monsoon trough) are defined as the monsoon environments (Wang et al. 2001). In contrast, the cluster types without the monsoon circulation and dominated by large-scale easterly flow are defined as the easterly environments. The 
(a) Type 1

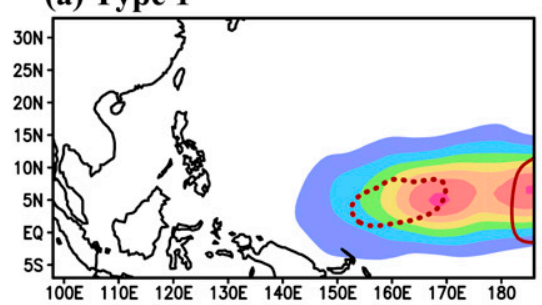

(d) Type 4

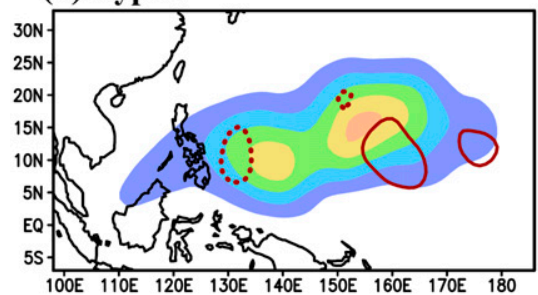

(g) Type 7

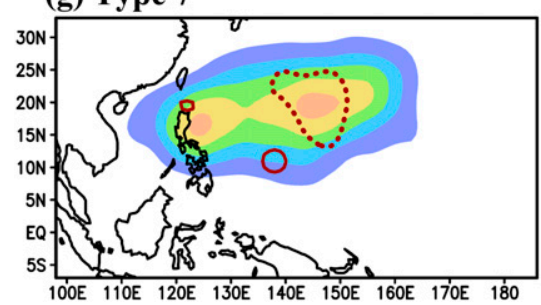

(b) Type 2

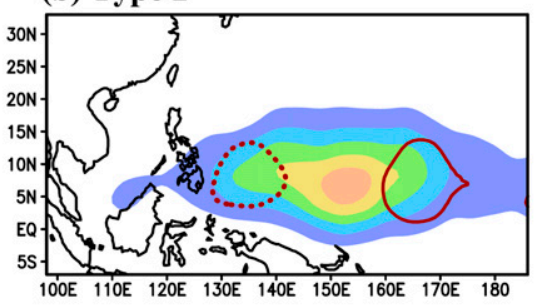

(e) Type 5

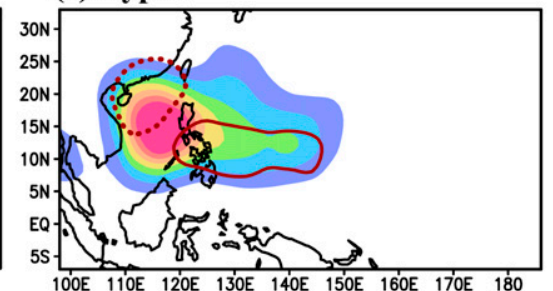

(h) Type 8

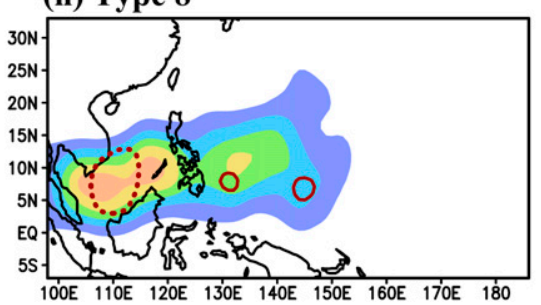

(c) Type 3

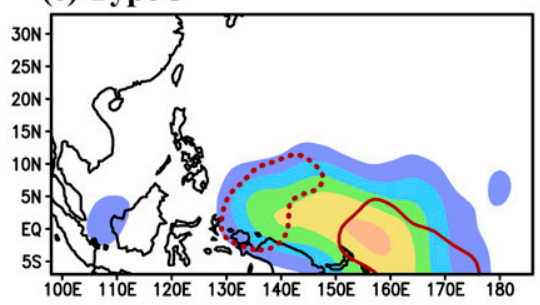

(f) Type 6

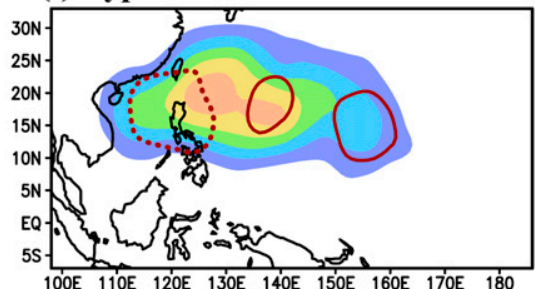

FIG. 4. TCC formation frequencies (\%) for eight cluster types (colored shading). The sum of all gridpoint values is $100 \%$ for each panel. Red solid and dashed contours are the $1.5 \%$ positive anomalies from the climatology for El Niño and La Niña years, respectively.

spatial distributions of TCC formation locations for each cluster type in the geographic coordinate are shown as formation frequency in Fig. 4. The formation frequency is defined as the number of TCCs formed in each grid box $\left(5^{\circ} \times 5^{\circ}\right)$ divided by the total TCC number in the domain, for each cluster type.

TCCs formed in cluster type 1 are in the strong easterlies in the low-latitude region of the eastern WNP (Figs. 3a and 4a), where the ITCZ is usually located. This cluster type has the highest number of TCCs. The locations of TCCs formed in the monsoon confluence zone (type 2, Figs. 3b and 4b) spread over a wider region in the zonal direction than for other cluster types. The formation locations for TCCs in cluster type 3 are the most southward of the eight cluster types (Figs. $3 \mathrm{c}$ and $4 \mathrm{c}$ ). TCC formations of this cluster type are associated with crossequatorial flow and their formation locations are located at low latitudes and relatively far from the monsoon trough. For cluster types 4 and 7, no monsoon trough circulation is observed. Although there is a weak confluence pattern in cluster type 7, the wind speed value of the southwesterly is so small that the monsoon circulation at the west of TCC formation location does not form clearly. Cluster types 4 and 7 are considered as the environments dominated by easterlies. Additionally, the TCCs are to the southwest (Figs. 3d and 4d) and the west of the subtropical high (Figs. $3 \mathrm{~g}$ and $4 \mathrm{~g}$ ), respectively.

Type 5 (Figs. $3 \mathrm{e}$ and $4 \mathrm{e}$ ) represents the monsoon trough environment in which TCCs form. In this cluster type, most TCCs are distributed in the South China Sea and the western WNP. Conversely, TCCs that form in the northern and southern boundaries of the monsoon trough are classified as type 6 (Figs. $3 \mathrm{f}$ and $4 \mathrm{f}$ ) and type 8 (Figs. $3 \mathrm{~h}$ and $4 \mathrm{~h}$ ), respectively. Although types 5, 6, and 8 all have a circulation pattern similar to that of a monsoon trough, the formation locations of TCCs relative to the trough differ significantly among different cluster types. Therefore, these environments must be classified into three groups.

Considering the circulation patterns and the formation locations of TCCs relative to the monsoon trough and the subtropical high, the TCC formations associated with environments of these eight cluster types can be presented in a schematic diagram as shown in Fig. 5. Note that the circulation and the relative location of each cluster type shown in Fig. 5 are relative to their climatological circulations (July-October 1981-2009).

The average $T_{b}$ anomaly around TCC center from the climatology, which is the average $T_{b}$ around TCC center 


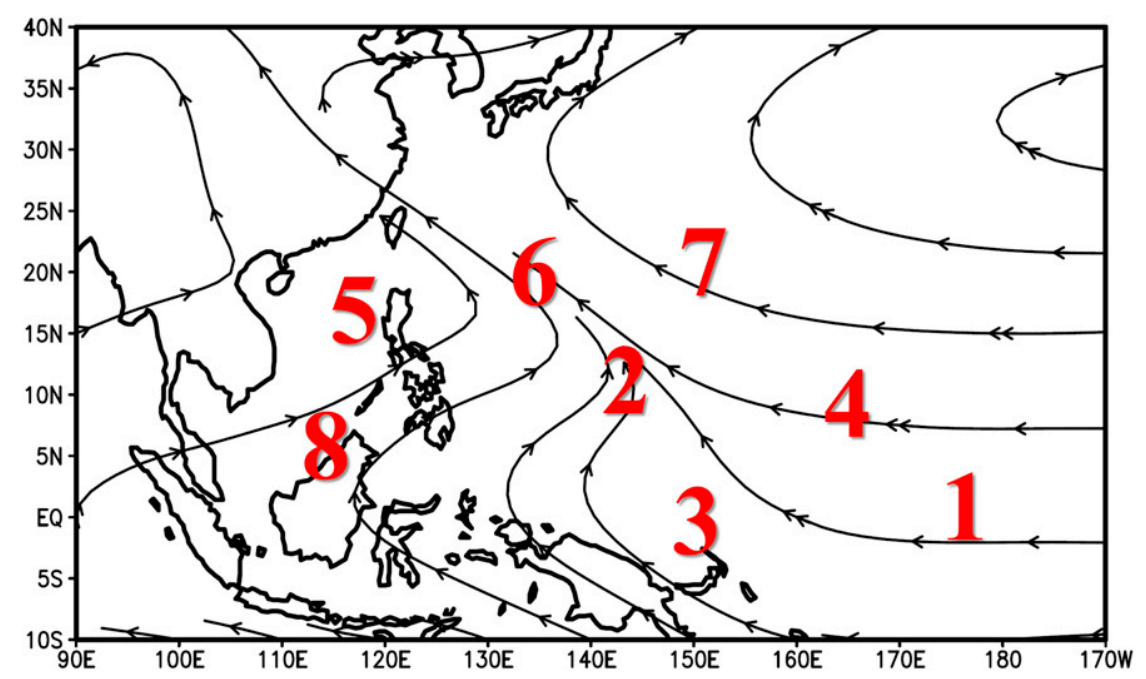

FIG. 5. Schematic diagram showing the climatology of 850-hPa streamlines (July-October, 1981-2009) and the relative locations and corresponding environments of TCC formations for eight cluster types.

for all clustering samples, for each cluster type is shown in Fig. 6. The average sizes of TCC and embedded MCS for each cluster type are shown in Table 1 . To calculate the sizes, the number of grid points that meet the TCC and MCS criteria (described in section 2a) is counted and translated into actual area $\left(\mathrm{km}^{2}\right)$ for each TCC. As Fig. 6 and Table 1 show, TCCs that form in the monsoon trough and north of monsoon trough environments (types 5 and 6 ) have lower $T_{b}$ and larger TCC and MCS areas than the climatology of all samples for all cluster types. Conversely, TCCs formed in low-latitude easterly, low-latitude cross-equatorial flow, and easterly at the southwest of subtropical high environments (types 1, 3, and 4) have relatively higher $T_{b}$ and smaller TCC and MCS areas.

Results (Table 1) also show that TCCs formed in the monsoon confluence (type $2,57.0 \mathrm{~h}$ ), monsoon trough (type $5,56.7 \mathrm{~h}$ ), and north of monsoon trough (type $6,57.1 \mathrm{~h}$ ) environments have statistically significant longer lifetimes than the average lifetime of all samples. Note that only those TCCs that do not develop into TCs (nondeveloping TCCs) are considered here. In contrast, TCCs formed in the lowlatitude easterly (type $1,44.1 \mathrm{~h}$ ), easterly at the southwest of subtropical high (type 4, 49.3 h), and south of monsoon trough (type $8,49.2 \mathrm{~h}$ ) environments are with shorter lifetimes. However, only the result for type 1 is statistically significant. Generally, TCCs formed in the monsoon environments (confluence, trough, and north of trough) have longer lifetime even though they do not develop into TCs.

\section{b. Interannual variability and ENSO modulation}

The time series of the annual number of TCCs formed in each cluster type is shown in Fig. 7. The coefficient of variation (i.e., the standard deviation divided by the mean) of the annual number is the smallest in types 2 and 8 , which indicates the relative dispersion level of their annual number is the smallest of all cluster types, while the coefficient of variation is the greatest in type 6 , based on the bootstrap $t$ test with a $95 \%$ confidence level. As shown in Table 2, although the number of total TCCs formed across the entire WNP does not have a statistically significant correlation with the ONI, the numbers of TCCs formed in the monsoon (types 2, 5, and 6) and low-latitude cross-equatorial flow (type 3) environments are positively correlated with the ONI. In addition, the numbers of TCCs formed in the easterly environments (types 1,4 , and 7) are negatively correlated with the ONI. All correlations for these seven cluster types are statistically significant. During El Niño years, more TCCs form in monsoon and low-latitude cross-equatorial flow environments, and fewer TCCs form in easterly environments (Table 2). During La Niña years, fewer TCCs form in monsoon environments and more TCCs form in easterly environments.

To reveal the modulation of TCC formation by ENSO in the subregions of the WNP, the correlation coefficients between the number of TCCs formed in each cluster type in the subregions of the WNP and the ONI are calculated and results are shown in Table 3. The differences in the TCC formation frequency for each cluster type between El Niño and La Niña years are shown in Fig. 4, and the circulation composites for El Niño and La Niña years are shown in Fig. 8. In the western WNP (Table 3), the number of TCCs is negatively correlated with the ONI. However, no significant 
(a) Type 1

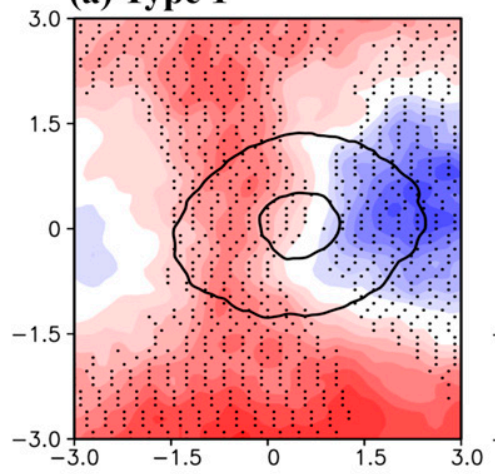

(d) Type 4

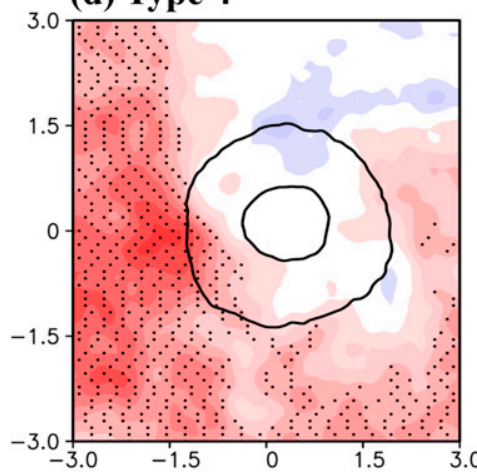

(g) Type 7

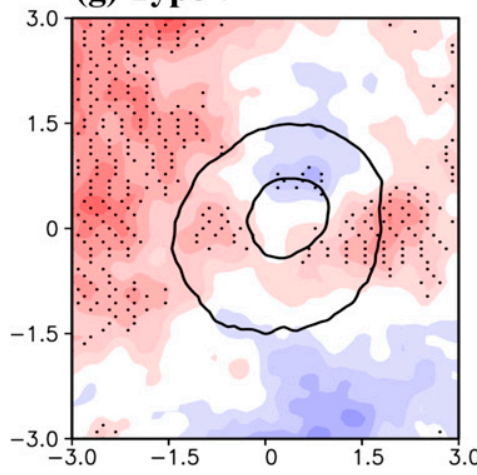

(b) Type 2

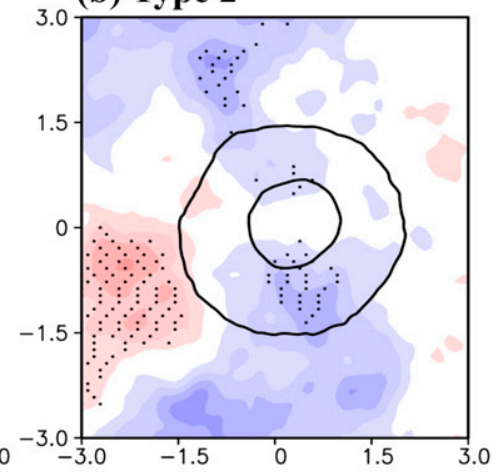

(e) Type 5

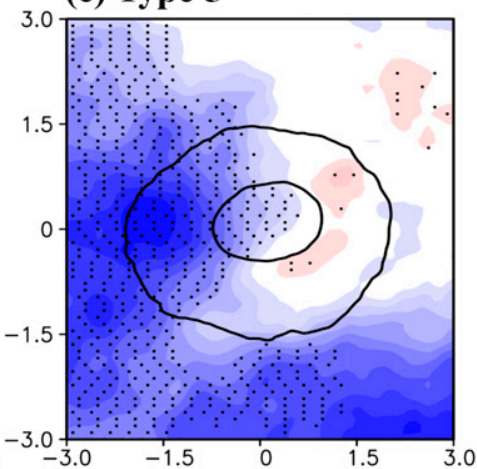

(h) Type 8

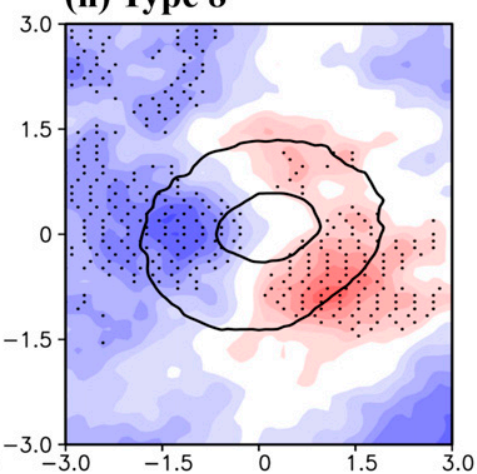

(c) Type 3

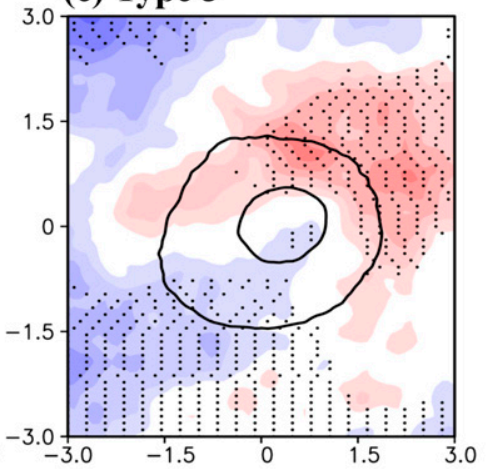

(f) Type 6

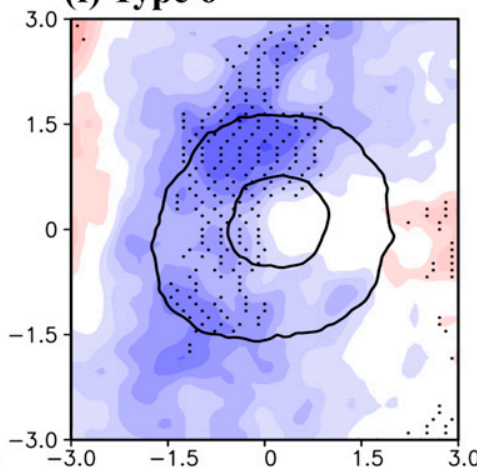

(i) All

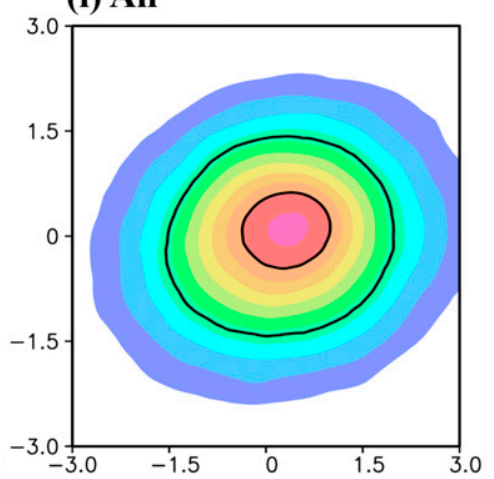

(K)

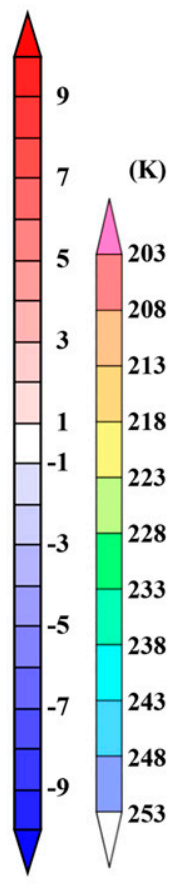

FIG. 6. (a)-(h) $T_{b}$ anomalies (colored shading) from the climatology for each cluster type and (i) the climatology of $T_{b}$, which is the average of all samples for all cluster types. The origin in each panel represents the location of TCC formation. The inner and outer black lines show the contours of composited $T_{b}$ at 208 and $235 \mathrm{~K}$, respectively. Black dots indicate the differences that pass the $t$ test at a $95 \%$ confidence level. The right color bar is for (i).

correlation exists between the ONI and the number of TCCs formed in monsoon trough, north of monsoon trough, and south of monsoon trough environments (types 5, 6, and 8). The negative correlation between TCC numbers in the western WNP and the ONI is mainly caused by the westward shift of the monsoon confluence (type 2) and easterly systems (types 4 and 7) into the western WNP during La Niña years, and the eastward shift out from the western WNP during El Niño years (Figs. 4 and 8).
For the eastern WNP (Table 3), however, the eastward extension of the monsoon trough during El Niño years causes an eastward shift of TCC formation locations associated with monsoon trough, monsoon confluence, and north of monsoon trough environments (types 2, 5, and 6; Figs. 4 and 8). The low-latitude crossequatorial flow (type 3 ) is also strengthened. Because the increase of TCC formations in monsoon and lowlatitude cross-equatorial flow environments is greater than the decrease in easterly environments, more TCCs 
(a) Type 1

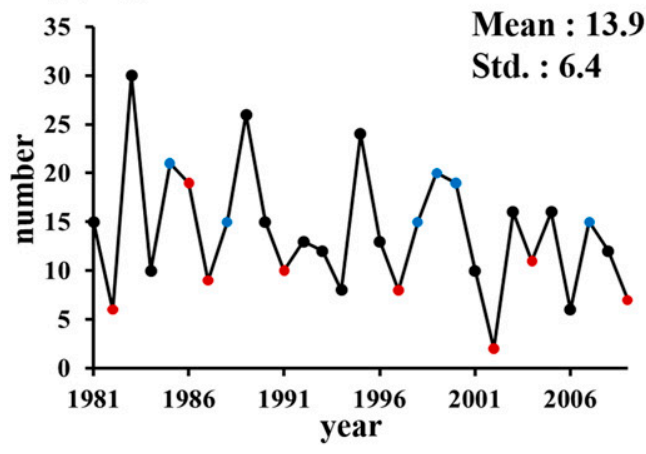

(c) Type 3

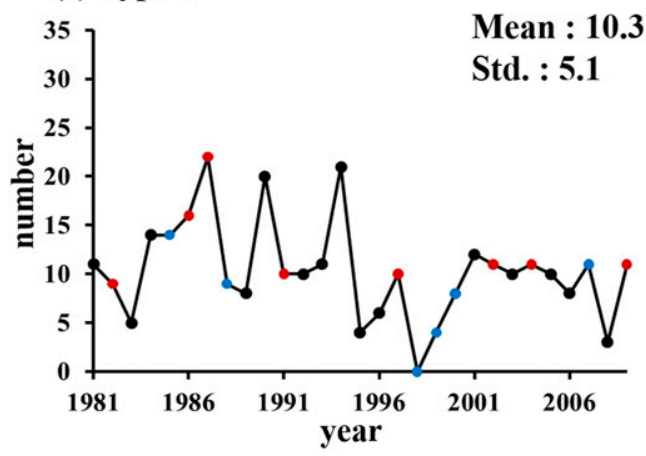

(e) Type 5

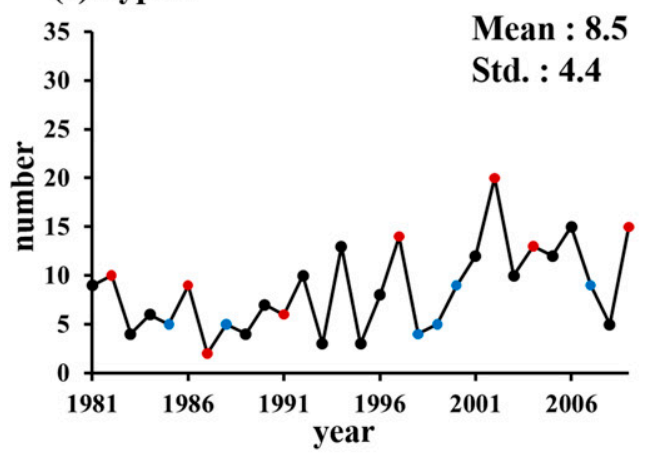

(g) Type 7

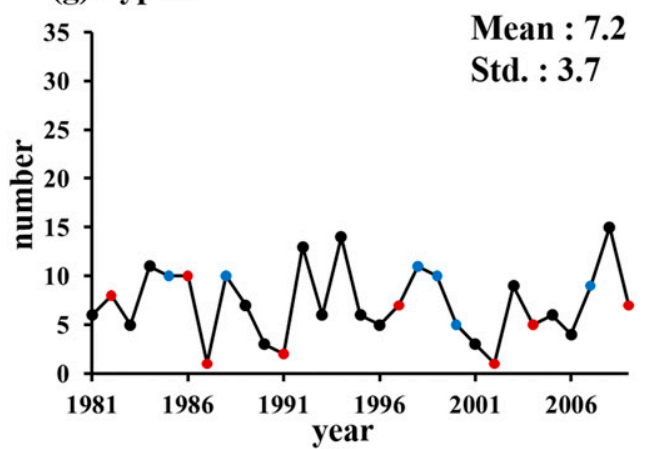

(b) Type 2

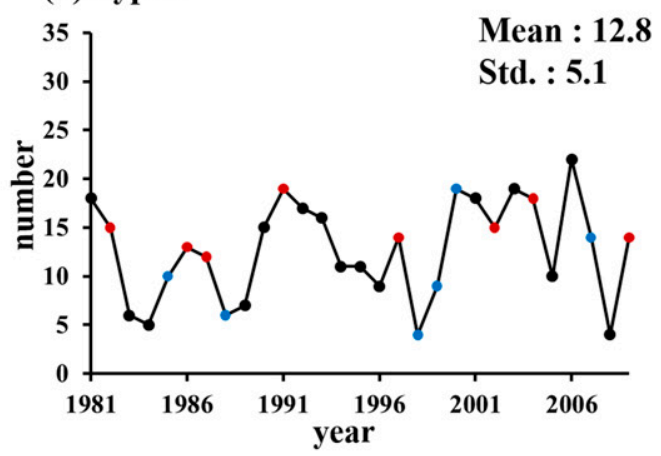

(d) Type 4

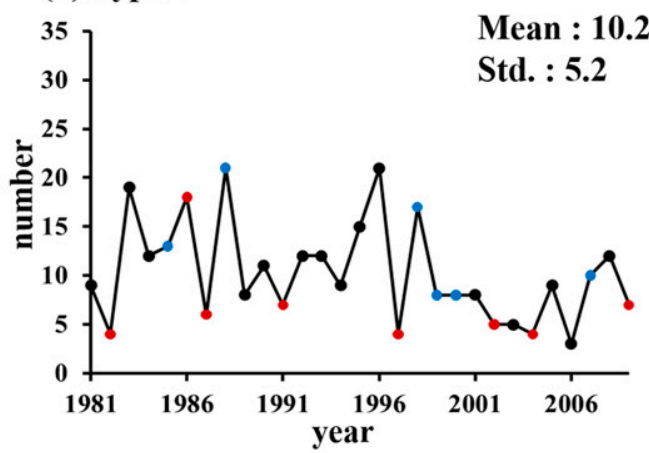

(f) Type 6

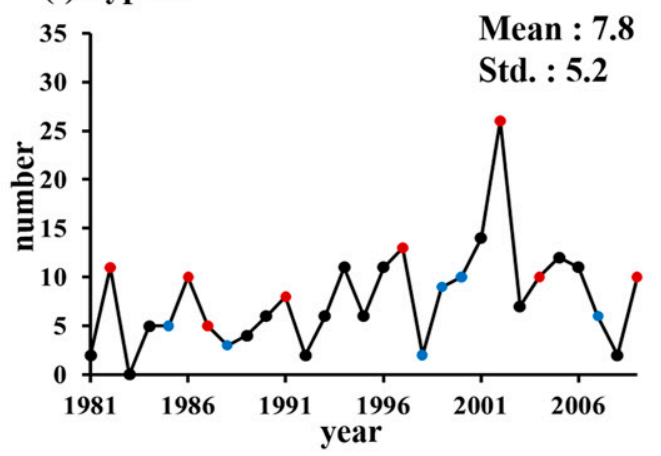

(h) Type 8

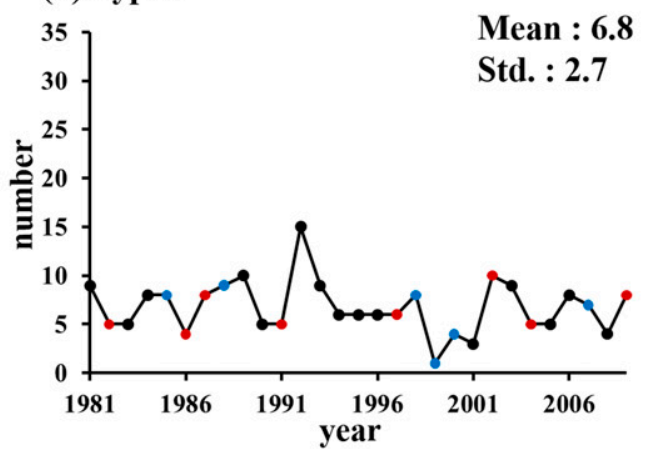

FIG. 7. Time series of the numbers of TCCs formed in eight cluster type environments. Black, red, and blue dots indicate the normal, El Niño, and La Niña years, respectively. 
TABLE 2. Average annual numbers of TCCs formed in the entire WNP for all years (All), El Niño, and La Niña years, and the correlation coefficients $(R)$ between the ONI and the annual TCC number for each cluster type. Single asterisks $(*)$ indicate that the difference between El Niño and La Niña years passes the $t$ test at a $95 \%$ confidence level, and double asterisks $(* *)$ indicate that the correlation coefficient passes the Pearson's correlation test at a $95 \%$ confidence level.

\begin{tabular}{lrrrr}
\hline \hline Cluster type & All & El Niño & La Niña & \multicolumn{1}{c}{$R$} \\
\hline Type 1 & 13.9 & $9.0^{*}$ & $17.5^{*}$ & $-0.56^{* *}$ \\
Type 2 & 12.8 & $15.0^{*}$ & $10.3^{*}$ & $0.43^{* *}$ \\
Type 3 & 10.3 & $12.5^{*}$ & $7.7^{*}$ & $0.50^{* *}$ \\
Type 4 & 10.2 & $6.9^{*}$ & $12.8^{*}$ & $-0.59^{* *}$ \\
Type 5 & 8.5 & $11.1^{*}$ & $6.2^{*}$ & $0.43^{* *}$ \\
Type 6 & 7.8 & $11.6^{*}$ & $5.8^{*}$ & $0.44^{* *}$ \\
Type 7 & 7.2 & $5.1^{*}$ & $9.2^{*}$ & $-0.39^{* *}$ \\
Type 8 & 6.8 & 6.4 & 6.2 & 0.03 \\
Total & 77.5 & 77.6 & 75.7 & 0.10 \\
\hline
\end{tabular}

form in the eastern WNP during El Niño years. The opposite situation occurs during La Niña years, and fewer TCCs form in the eastern WNP. Therefore, a positive correlation between TCC number and the ONI exists in the eastern WNP.

\section{Environmental conditions of TCC formations}

The differences in the environmental conditions of TCC formation are analyzed further in this section to highlight the differences between different cluster types, namely the monsoon environments and easterly environments, and between developing and nondeveloping TCCs. The average environmental parameters around the location of TCC formation are used to represent the environmental conditions of TCC formation. To assess comprehensively how favorable the environmental conditions are for TC formation, the genesis potential index (GPI; Emanuel and Nolan 2004) is used. The GPI

\section{(a) El Niño}

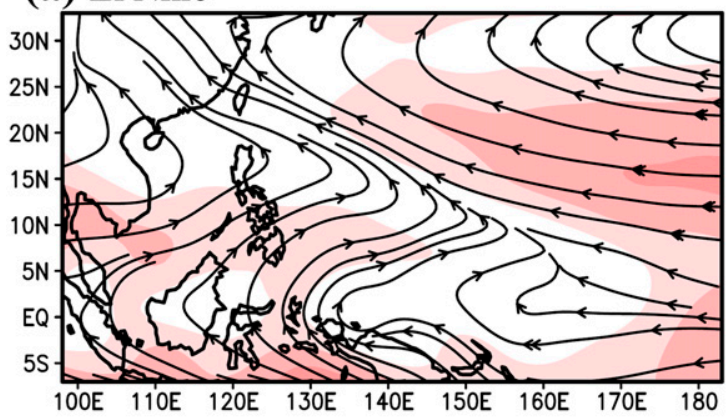

(b) La Niña

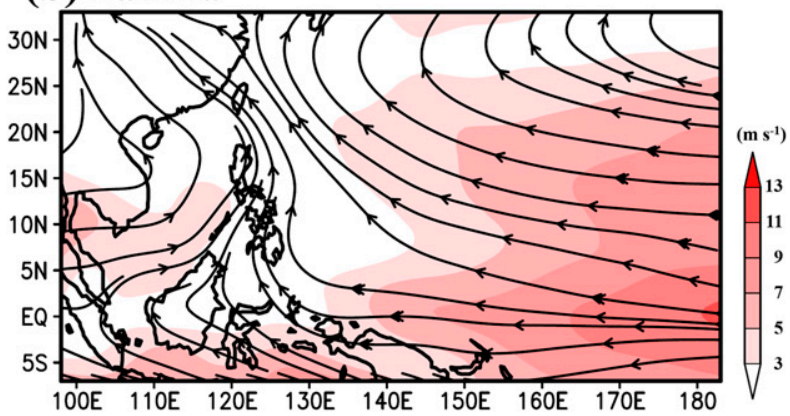

FIG. 8. Composites of $850-\mathrm{hPa}$ streamlines and wind speeds (colored shading) during July-October, 1981-2009 for (a) El Niño and (b) La Niña years.

considers $850-\mathrm{hPa}$ absolute vorticity, $600-\mathrm{hPa}$ relative humidity, maximum potential intensity (Bister and Emanuel 2002), and 200-850-hPa vertical wind shear. The GPI is regarded as a parameter to represent how favorable an environment is to TC formation, and has been used to diagnose environmental conditions on TC formation for climate and seasonal scales (Camargo et al. 2007a,b; Bruyère et al. 2012; Zhao et al. 2015) and for synoptic scales (Satoh et al. 2013; Yoshida and Ishikawa 2013).

TABLE 3. Average annual numbers of TCCs formed in the (left) western and the (right) eastern WNP during El Niño and La Niña years, and the correlation coefficients $(R)$ between the ONI and the annual TCC number for each cluster type. Single asterisks $(*)$ indicate that the difference between El Niño and La Niña years passes the $t$ test at a $95 \%$ confidence level, and double asterisks (**) indicate that the correlation coefficient passes the Pearson's correlation test at a $95 \%$ confidence level.

\begin{tabular}{|c|c|c|c|c|c|c|}
\hline \multirow[b]{2}{*}{ Cluster type } & \multicolumn{3}{|c|}{ Western WNP } & \multicolumn{3}{|c|}{ Eastern WNP } \\
\hline & El Niño & La Niña & $R$ & El Niño & La Niña & $R$ \\
\hline Type 1 & $0.4^{*}$ & $1.2 *$ & $-0.51 * *$ & $8.6^{*}$ & $16.3^{*}$ & $-0.51 * *$ \\
\hline Type 2 & $1.9^{*}$ & $4.7^{*}$ & $-0.45^{* *}$ & $13.1^{*}$ & $5.7 *$ & $0.59 * *$ \\
\hline Type 3 & $1.5^{*}$ & $3.5^{*}$ & $-0.35^{* *}$ & $11.0^{*}$ & $4.2 *$ & $0.64 * *$ \\
\hline Type 4 & $1.3^{*}$ & $5.0^{*}$ & $-0.59 * *$ & 5.6 & 7.8 & $-0.41 * *$ \\
\hline Type 5 & 8.0 & 6.0 & 0.22 & $3.1^{*}$ & $0.2 *$ & $0.58 * *$ \\
\hline Type 6 & 6.0 & 5.0 & 0.14 & $5.6^{*}$ & $0.8^{*}$ & $0.66^{* *}$ \\
\hline Type 7 & 2.4 & 4.5 & $-0.39 * *$ & 2.8 & 4.7 & -0.21 \\
\hline Type 8 & 3.5 & 4.3 & -0.12 & 2.9 & 1.8 & 0.28 \\
\hline Total & $24.9 *$ & $34.2 *$ & $-0.70 * *$ & $52.8^{*}$ & $41.5^{*}$ & $0.51 * *$ \\
\hline
\end{tabular}


(a) Type 1

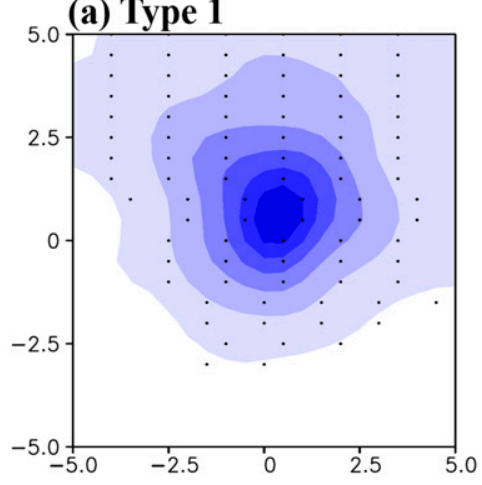

(d) Type 4

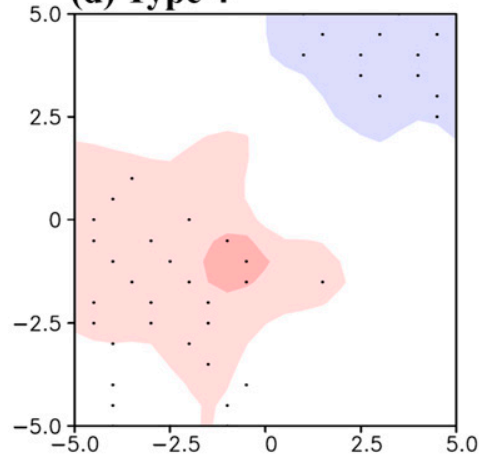

(g) Type 7

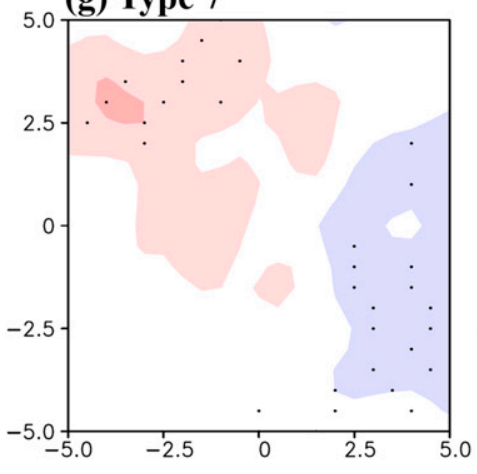

(b) Type 2

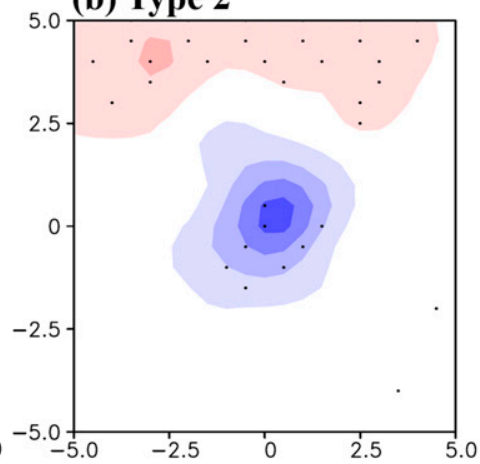

(e) Type 5

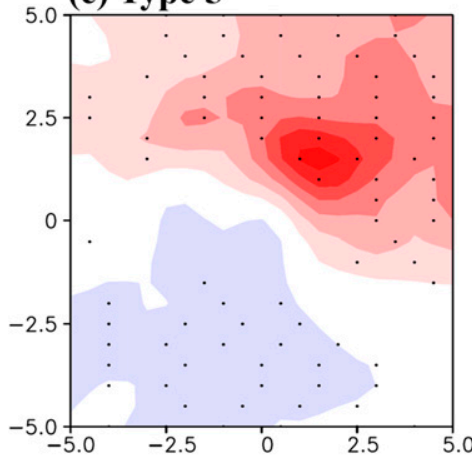

(h) Type 8

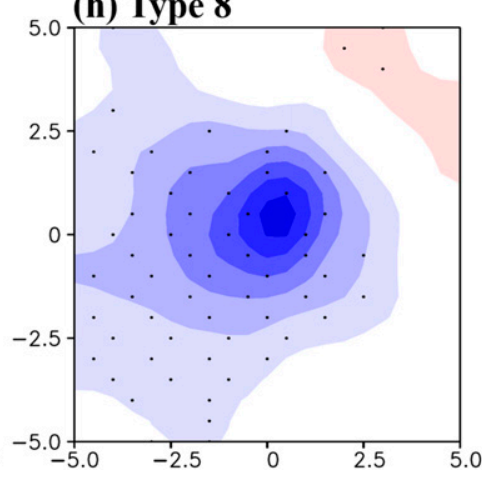

(c) Type 3

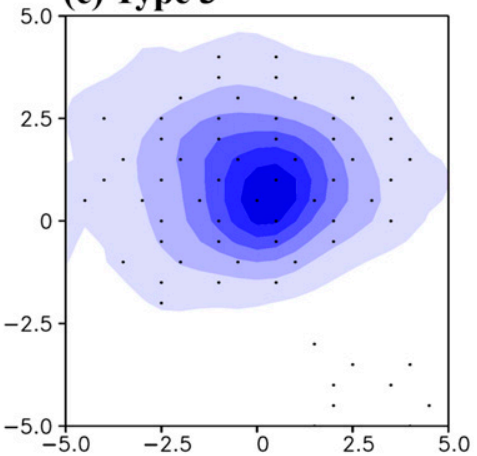

(f) Type 6

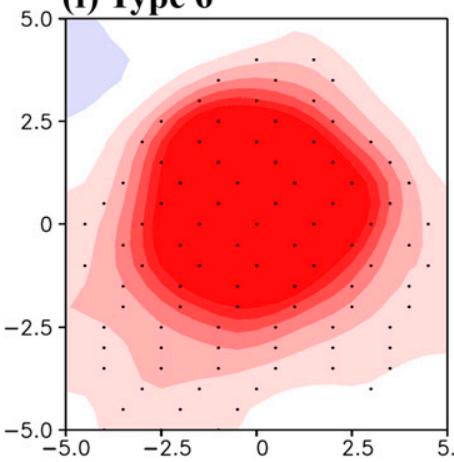

(i) All

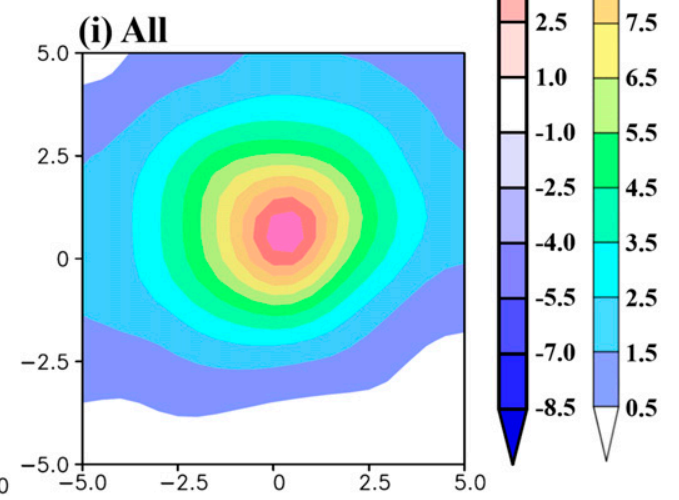

FIG. 9. (a)-(h) Differences of GPI anomaly (colored shading) between each cluster type and the climatology and (i) the climatology of GPI anomaly, which is the average of all samples for all cluster types. The origin in each panel represents the location of TCC formation. Black dots indicate the differences that pass the $t$ test at a $95 \%$ confidence level. The right color bar is for (i).

In this study, the GPI is calculated at each grid point around the location of TCC formation for every clustering sample. The GPI values for all samples of each cluster type are then composited to show the average environmental conditions where the TCCs form for every cluster type. Because the difference of seasonality might affect the magnitude of GPI, the GPI anomaly from the daily climatology during 1979 to 2010 is used. Thus, the GPI composite for each cluster type is defined as the composite of GPI anomalies of all samples in each cluster type.
Besides the GPI composite, the cumulative distribution function (CDF) of area-averaged values of GPI anomalies is also calculated for each cluster type to highlight the sample distribution of GPI values within each cluster type and its difference between different cluster types. Here the area average is taken to be the average inside $5^{\circ}$ radius from the TCC center at the time of TCC formation. To calculate the CDF, all selected samples are ranked from the minimum to the maximum based on their values of area-averaged GPI. Then, the percentile of each GPI magnitude is obtained, which is 
(a) Type 1

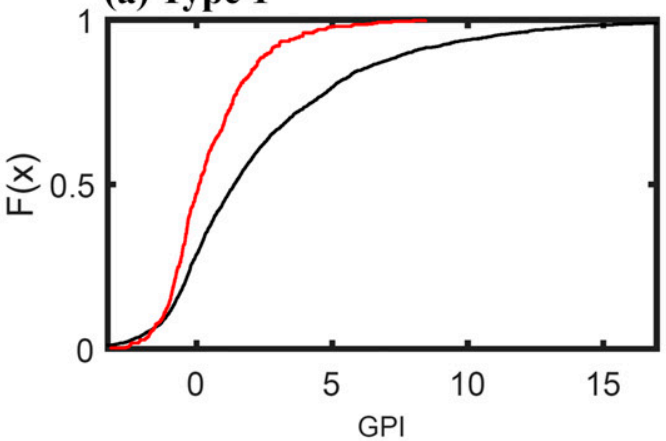

(c) Type 3

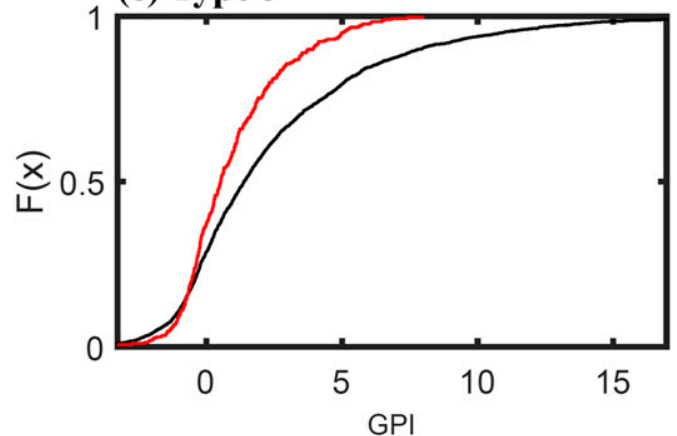

(e) Type 5

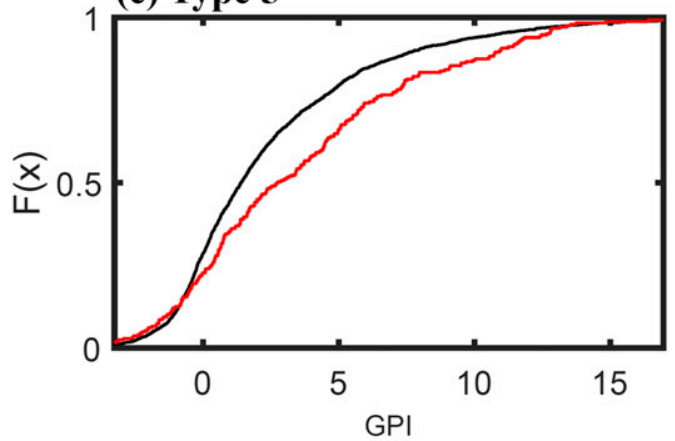

(g) Type 7

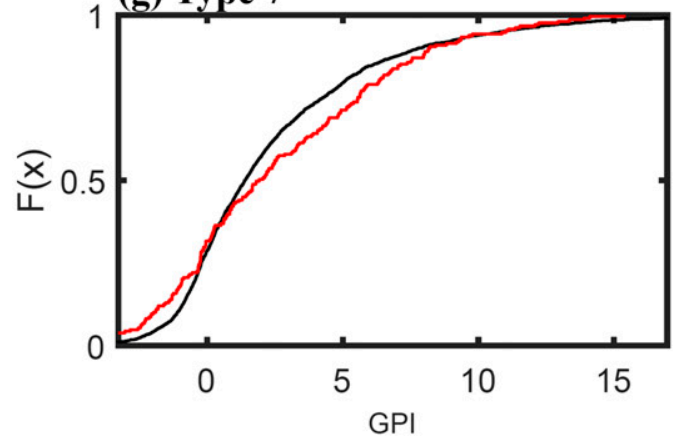

(b) Type 2

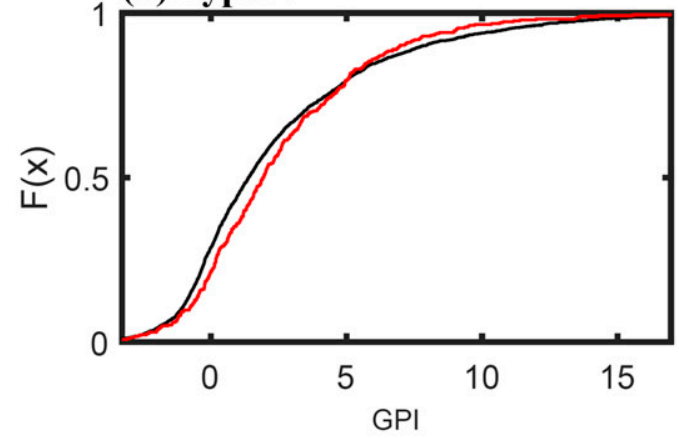

(d) Type 4

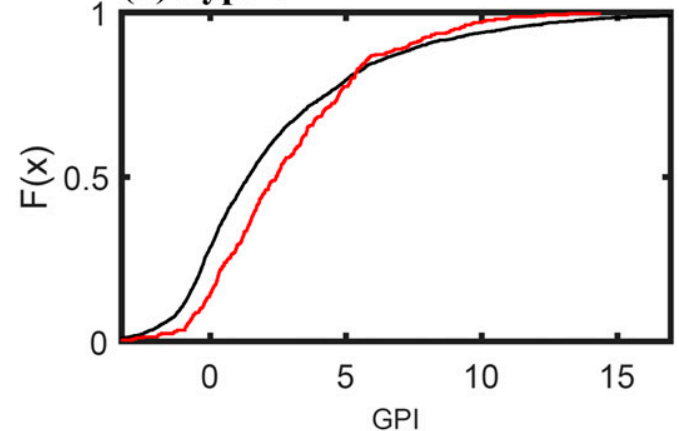

(f) Type 6

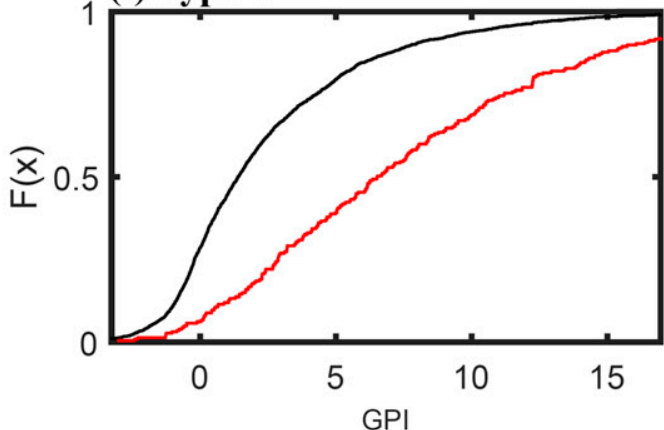

(h) Type 8

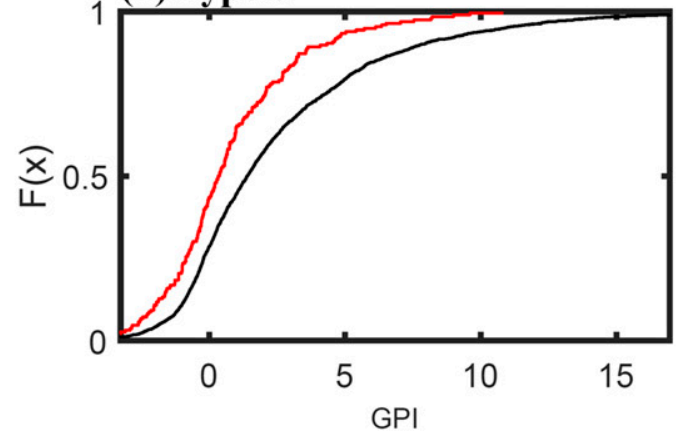

FIG. 10. CDFs of the area-averaged GPI for each cluster type (red curve) and the climatology (black curve), which is for all samples of all cluster types. The CDF window only shows data from $1 \%$ to $99 \%$ of the black curve.

presented as a CDF curve. To evaluate the difference between two CDF curves, the Kolmogorov-Smirnov (KS) test is performed to determine the significance of the differences, including the differences in means, standard deviations, and distribution peaks. Because the KS test does not reflect what makes differences significant, the Student's $t$ test is also used to examine the differences in means between any two groups, 
TABLE 4. Results of the KS test and $t$ test of the differences between two selected groups. The circles indicate that the differences pass the test at a $95 \%$ confidence level, and the crosses indicate those that do not pass the test.

\begin{tabular}{|c|c|c|}
\hline Difference between two groups & Kolmogorov-Smirnov test & $t$ test \\
\hline Type 1 and climatology & $\bigcirc$ & $\bigcirc$ \\
\hline Type 2 and climatology & $\bigcirc$ & $x$ \\
\hline Type 3 and climatology & $\bigcirc$ & $\bigcirc$ \\
\hline Type 4 and climatology & $\bigcirc$ & $\bigcirc$ \\
\hline Type 5 and climatology & O & $\bigcirc$ \\
\hline Type 6 and climatology & O & $\bigcirc$ \\
\hline Type 7 and climatology & $\times$ & $\times$ \\
\hline Type 8 and climatology & $\bigcirc$ & $\bigcirc$ \\
\hline Developing and nondeveloping TCCs formed in easterly & $\bigcirc$ & $\bigcirc$ \\
\hline Developing and nondeveloping TCCs formed in monsoon & $\bigcirc$ & $\times$ \\
\hline Developing TCCs formed in easterly and monsoon & $\times$ & $x$ \\
\hline Nondeveloping TCCs formed in easterly and monsoon & $\bigcirc$ & $\bigcirc$ \\
\hline
\end{tabular}

when comparing the area-averaged GPIs between two cluster types.

\section{a. GPI for the eight cluster types}

Figure 9 shows the difference in the composite of GPI anomalies between each cluster type and the climatology. The climatology is defined as the average of GPI anomalies for all samples of all cluster types. Results show that the GPI is much higher than that of the climatology over an area of $3^{\circ}$ radius for the north of monsoon trough environment (type 6, Fig. 9f), which is statistically significant based on the $t$ test at a $95 \%$ confidence level. GPI values are also higher in an area to the northeast of TCC formation location for the monsoon trough environment (type 5, Fig. 9e) and in an area to the southwest of TCC formation location for the easterly environment southwest of the subtropical high (type 4, Fig. 9d). In contrast, GPI values are significantly lower in an area inside $2^{\circ}-2.5^{\circ}$ radius for low-latitude easterly, low-latitude cross-equatorial flow, and south of monsoon trough environments (types 1, 3, and 8; Figs. 9a,c,h). For monsoon confluence environment (type 2, Fig. 9b), the GPI values are also lower but only in an area inside $1^{\circ}-1.5^{\circ}$ radius. The area where the difference passes the $t$ test is even smaller.

The CDF of area-averaged GPIs for each cluster type is shown in Fig. 10 (red curve). The curve of climatology (black curve in Fig. 10) indicates the distribution of areaaveraged GPIs for all samples of all cluster types and is considered as a relative reference to compare with for each cluster type. Table 4 shows that whether the difference between each cluster type and the climatology is statistically significant or not, based on the KS test and the $t$ test. Results show that, for monsoon trough and north of monsoon trough environments (types 5 and 6), the area-averaged GPIs are significantly higher than the climatology. Such results are mainly because the area averages of 850-hPa vorticity for types 5 and 6 (1.66 and $\left.2.9010^{-5} \mathrm{~s}^{-1}\right)$ are much higher than that of the climatology $\left(0.8510^{-5} \mathrm{~s}^{-1}\right)$ and the differences are statistically significant. The means of area-averaged GPIs for monsoon confluence and easterly environment at the west of subtropical high (types 2 and 7) are similar to that of the climatology. Similar to Fig. 9, the areaaveraged GPIs are lower and statistically significant than the climatology for three cluster types (i.e., types 1 , 3, and 8; Fig. 10 and Table 4), which also have the lowest number and percentage of TCCs that develop into TCs (Table 1). In summary, the environmental conditions for TC formation are significantly different across cluster types. The number of developing TCCs and the percentage of TC number to TCC number are also different for different cluster types.

\section{b. Developing and nondeveloping TCCs}

When analyzing the differences in GPI between the developing and nondeveloping TCCs, three cluster types with the lowest GPI values (i.e., types 1, 3, and 8) are excluded. The remaining five cluster types are then divided into two groups: monsoon environments (types 2, 5, and 6) and easterly environments (types 4 and 7). Therefore, the environmental conditions are averaged for 4 categories: developing and nondeveloping TCCs formed in the monsoon and easterly environments. The spatial distributions of the differences of GPI anomalies between the categories are shown in Fig. 11. Similar to those shown in Fig. 10, the CDFs of area-averaged GPI anomalies for these 4 categories are shown in Fig. 12. The statistical significance of the differences between any two categories is presented in Table 4 . Note that the composite, CDF, and mean of developing TCCs formed in monsoon environments consider all developing TCCs in cluster types 2,5 , and 6 . The situation is similar for other categories. 
(a)

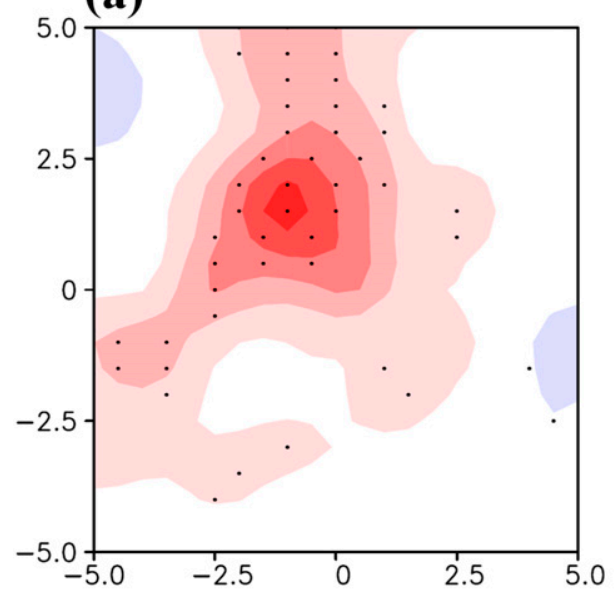

(c)

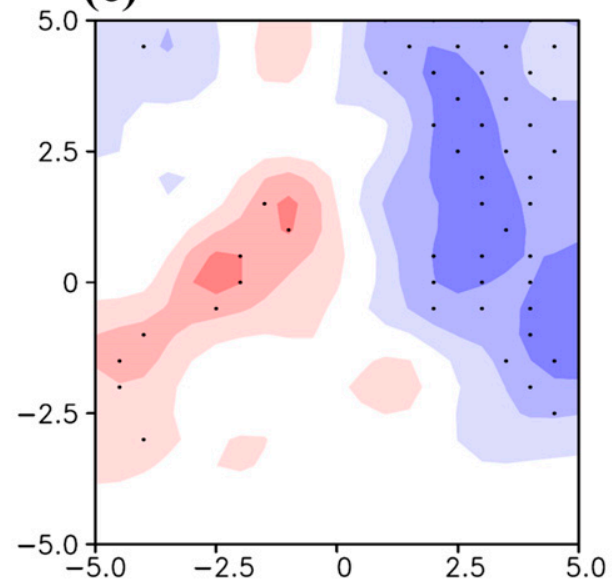

(b)

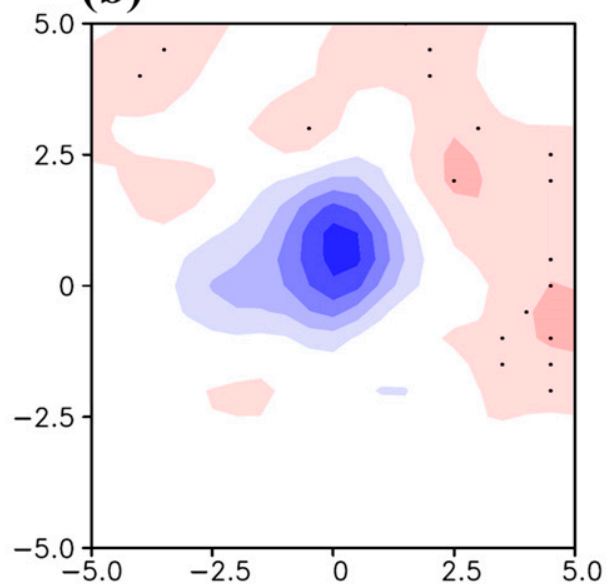

(d)

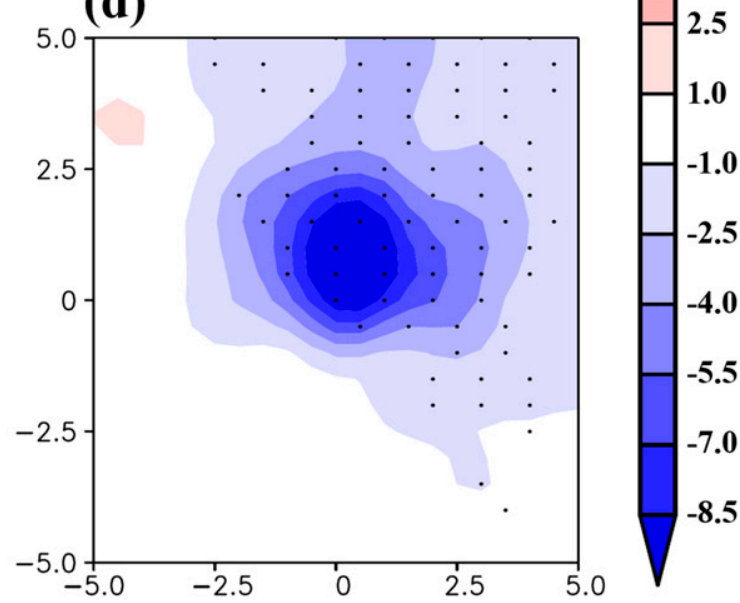

8.5

7.0

5.5 4.0

.0

1.0

$-2.5$

4.0

$-5.5$

$-7.0$

$-8.5$

FIG. 11. Differences of GPI anomaly (colored shading) between two specific groups: (a) developing and nondeveloping TCCs formed in easterly environments, (b) developing and nondeveloping TCCs formed in monsoon environments, (c) developing TCCs formed in easterly and monsoon environments, and (d) nondeveloping TCCs formed in easterly and monsoon environments. The origin in each panel represents the location of TCC formation. Black dots indicate the differences that pass the $t$ test at a $95 \%$ confidence level.

For easterly environments, the GPI is higher for developing TCCs than that for nondeveloping TCCs and the difference is statistically significant (Fig. 11a). As shown in Fig. 12 (red curves), the CDF curves for the developing and nondeveloping TCCs are different, and the differences in both the CDF curve and the mean value are statistically significant (Table 4). For monsoon environments, although the GPI near the location of TCC formation is lower for developing TCCs than that for nondeveloping TCCs, the difference is not statistically significant (Fig. 11b). Figure 12 (blue curves) shows that there are apparent differences in CDF curves between developing and nondeveloping TCCs, because the CDF of developing TCCs is higher than that of nondeveloping TCCs in the low GPI values and is lower than that of nondeveloping TCCs in the high GPI values.
These differences are statistically significant according to the KS test (Table 4). However, the difference in the mean values of area-averaged GPIs between developing and nondeveloping TCCs does not pass the significance test.

If only developing TCCs are considered (Fig. 11c), the GPI for TCCs formed in easterly environments is higher than that for TCCs formed in monsoon environments at the southwest of TCC formation location but is lower at the east of TCC formation location. However, neither the CDF curve nor the mean differs significantly for area-averaged GPI (Fig. 12 and Table 4). For nondeveloping TCCs, the GPI for TCCs formed in monsoon environments is higher than that for TCCs formed in easterly environments (Fig. 11d). Similar results are also found in CDF analysis (Fig. 12 and Table 4). In 


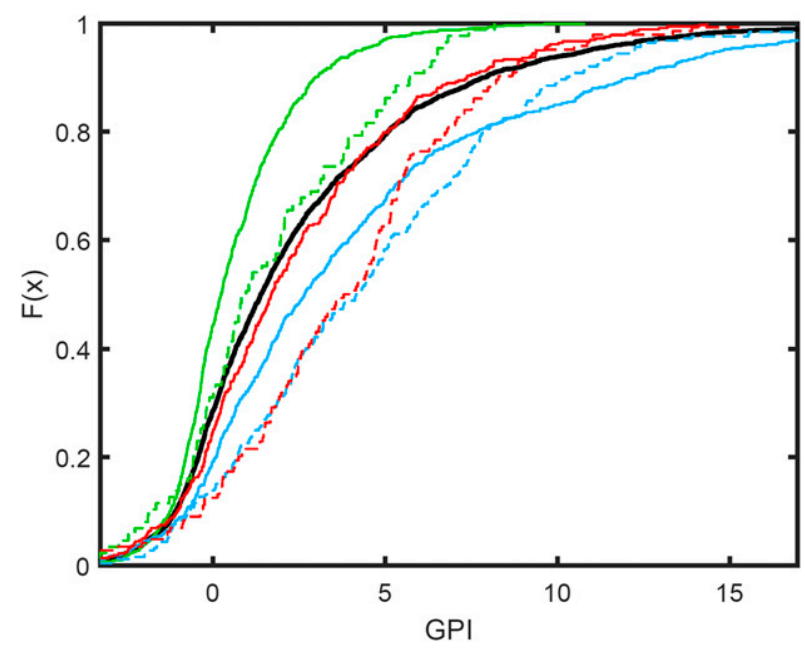

FIG. 12. CDFs of the area-averaged GPIs for developing (dashed) and nondeveloping (solid) TCCs formed in easterly (red), monsoon (blue), and three with the lowest GPI (green) environments and the climatology (black), which is for all samples of all cluster types. The CDF window only shows data from $1 \%$ to $99 \%$ of the black curve.

summary, although the area-averaged GPI for nondeveloping TCCs formed in monsoon environments is higher than that for nondeveloping TCCs formed in easterly environments, the area-averaged GPIs for developing TCCs are similar, no matter if TCCs form in monsoon or easterly environments.

To further understand the contribution of individual parameters to the difference of area-averaged GPIs between developing and nondeveloping TCCs, individual parameters considered in the GPI are analyzed. Figure 13 shows the differences of the radial-vertical cross sections of the azimuthal averages of relative vorticity and relative humidity between developing and nondeveloping TCCs formed in easterly and monsoon environments. On the other hand, Fig. 14 shows the differences of maximum potential intensity and vertical wind shear over an area of $20^{\circ} \times 20^{\circ}$ around the TCC formation location.

Results show that, for TCCs formed in easterly environments, the relative vorticity around the TCC center (Fig. 13a) and the maximum potential intensity to the south of TCC formation location (Fig. 14a) are much higher for developing TCCs than those for nondeveloping TCCs. The area-averaged $850-\mathrm{hPa}$ relative vorticity and maximum potential intensity inside $5^{\circ}$ radius are significantly higher for developing TCCs than those for nondeveloping TCCs (Table 5). However, the differences in the area-averaged $600-\mathrm{hPa}$ relative humidity and $200-850-\mathrm{hPa}$ vertical wind shear inside $5^{\circ}$ radius between developing and nondeveloping TCCs are not significant (Table 5). Moreover, note that, regardless of developing and nondeveloping TCCs, the area-averaged 850 -hPa relative vorticity, $600-\mathrm{hPa}$ relative humidity, and 200-850-hPa vertical wind shear of easterly environments are significantly lower than those of monsoon environments.

For TCCs formed in monsoon environments, the relative vorticity around the center of developing TCCs is lower than that around nondeveloping TCCs (Fig. 13b), but the difference in the area-averaged $850-\mathrm{hPa}$ relative vorticity inside $5^{\circ}$ radius between developing and nondeveloping TCCs is not statistically significant (Table 5). The maximum potential intensity to the north of TCC formation location (Fig. 14b) and its area average inside $5^{\circ}$ radius (Table 5) for developing TCCs are significantly higher than those for nondeveloping TCCs. Although the relative humidity above $500 \mathrm{hPa}$ is significantly higher (Fig. 13d) and the vertical wind shear to the northwest of TCC formation location is significantly lower (Fig. 14d) for developing TCCs than those for nondeveloping TCCs, the differences of the areaaveraged $600-\mathrm{hPa}$ relative humidity and vertical wind shear inside $5^{\circ}$ radius are not statistically significant (Table 5). Since the differences in the area-averaged $850-\mathrm{hPa}$ relative vorticity, $600-\mathrm{hPa}$ relative humidity, and $200-850-\mathrm{hPa}$ vertical wind shear between developing and nondeveloping TCCs inside $5^{\circ}$ radius are not statistically significant, the area-averaged GPIs for developing and nondeveloping TCCs are not significantly different.

In summary, analyzing the CDF curves and the means of area-averaged GPI shows that the area-averaged GPI of developing TCC is higher and statistically significant than that of nondeveloping TCC in easterly environments. Therefore, the environmental conditions are important to dictate whether a TCC will develop into a TC when it just formed in easterly environments. However, the influence of environmental conditions around TCC formation location is not found to be significant for the TCC development into a TC in the monsoon environments.

\section{Discussion and conclusions}

TCCs are the precursors of TCs. Many previous studies have analyzed TCCs in specific periods, cases, and observation experiments, even with long-term statistics (Williams and Houze 1987; Lee 1989; Mapes and Houze 1993; Gray 1998; Wang et al. 2007; Bessho et al. 2010; Hennon et al. 2011, 2013; Kerns and Chen 2013, 2015; Teng et al. 2014), but the characteristics of TCCs formed in different environments remain less clear. This is the first study that uses the nonhierarchical cluster 
(a) Relative vorticity

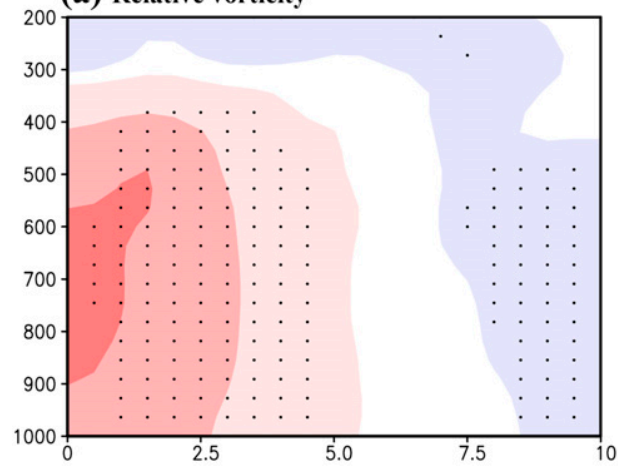

(c) Relative humidity

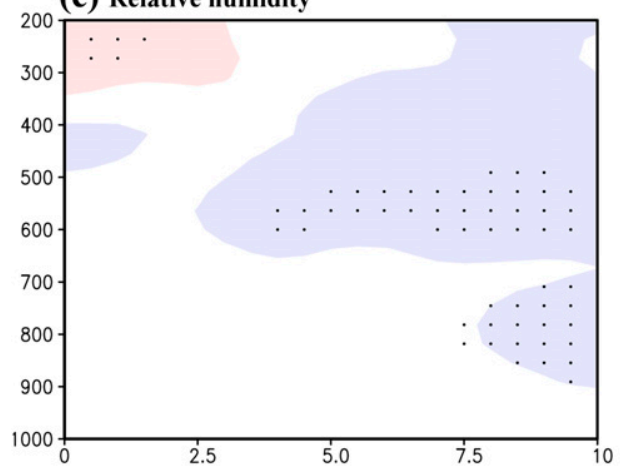

(b) Relative vorticity

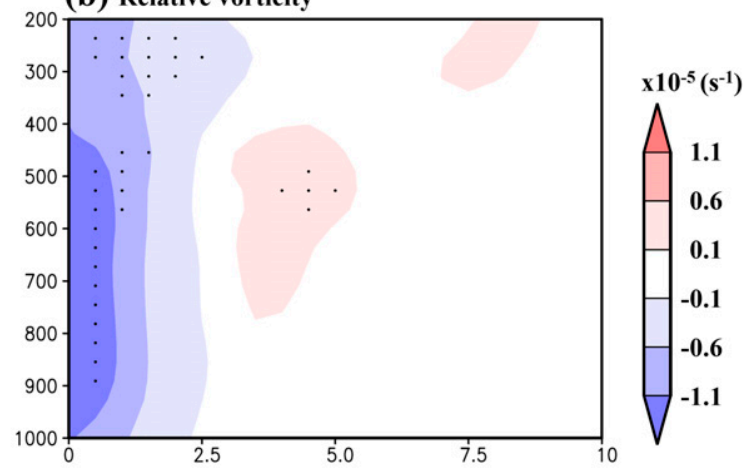

(d) Relative humidity

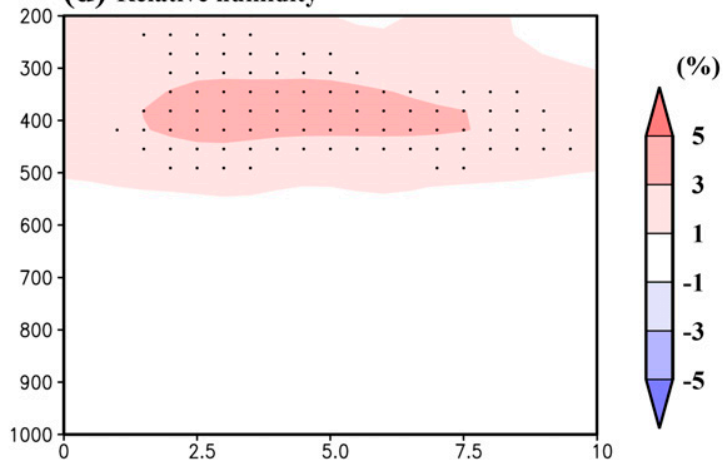

FIG. 13. Differences in azimuthal-averaged (a),(b) relative vorticity and (c),(d) relative humidity between developing and nondeveloping TCCs formed in (left) easterly and (right) monsoon environments. The $x$ axis is the radius $\left(^{\circ}\right)$ and $y$ axis is the pressure level $(\mathrm{hPa})$. The black dots indicate the differences that pass the $t$ test at a $95 \%$ confidence level.

analysis ( $k$-means clustering) with relative coordinates (in space and time) to analyze the wind field based on the location and time of each TCC formation to separate the major relevant environmental circulation patterns. The different circulation types associated with TCC formation are classified as follows: four are related to monsoon environments, three are related to easterly environments, and one is associated with low-latitude cross-equatorial flow. The number, formation location, convective pattern, and lifetime of TCCs formed in each cluster type environment are different. The modulation of ENSO on each cluster type is also different.

On average, TCCs formed in cluster types 1,3 , and 8 (low-latitude easterly zone, low-latitude cross-equatorial flow, and south of monsoon trough environments) are associated with the lowest GPI values. The numbers of TCCs that develop into TCs are also the lowest for these three cluster types. For the other cluster types, the TCCs formed in monsoon environments (types 2, 5, and 6) have longer lifetimes than the TCCs formed in easterly environments (types 4 and 7). Note that the lifetime is only considered for the nondeveloping TCCs. In particular, TCCs formed in monsoon trough and north of monsoon trough environments (types 5 and 6) have larger sizes, larger embedded MCSs, and lower $T_{b}$ than those of TCCs formed in other environments.

Relative to TCCs formed in easterly environments, TCCs formed in monsoon environments have higher GPIs (Figs. 9-12). Note that an environment with higher low-level vorticity, higher midlevel relative humidity, and lower vertical wind shear (i.e., higher GPI) favors the formation of a disturbance with lower $T_{b}$, larger size, and longer lifetime (Machado et al. 1993; Machado and Rossow 1993; Mapes and Houze 1993; Liu and Chan 2002; Hill and Lackmann 2009; Lee et al. 2008, 2010; Chen et al. 2011, 2012). However, although the monsoon environment is more favorable for the formation of larger TCCs and MCSs, the correlation coefficient between the annual number of TCCs that develop into TCs and the annual mean sizes of TCCs and MCSs is only -0.06 and 0.08 , respectively. These correlations are statistically nonsignificant based on the Pearson's correlation test at a $95 \%$ confidence level. The average percentages of TCCs that develop into TCs have no significant difference between TCCs formed in monsoon and easterly environments $(32.0 \%$ and $31.6 \%$, 
(a) Maximum potential intensity

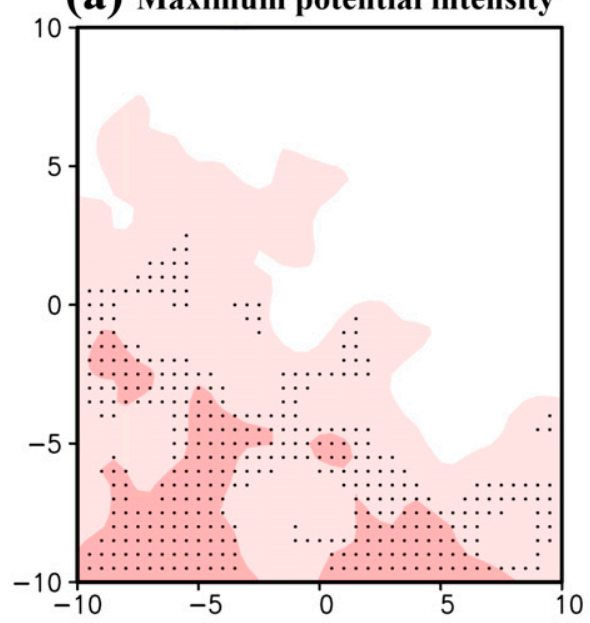

(c) Vertical wind shear

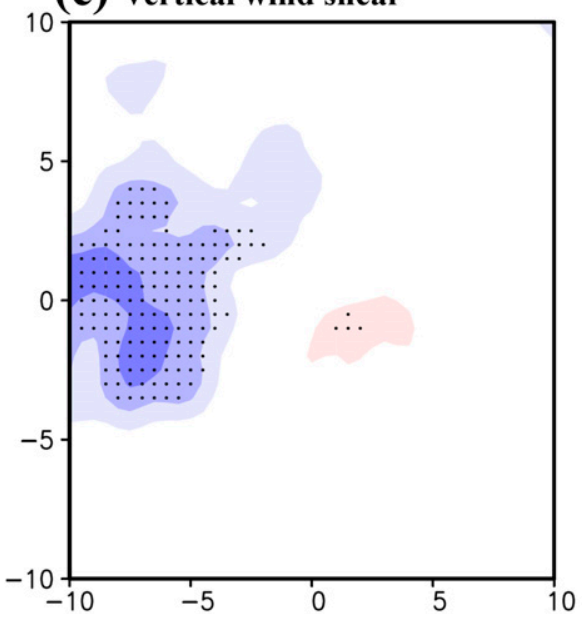

(b) Maximum potential intensity
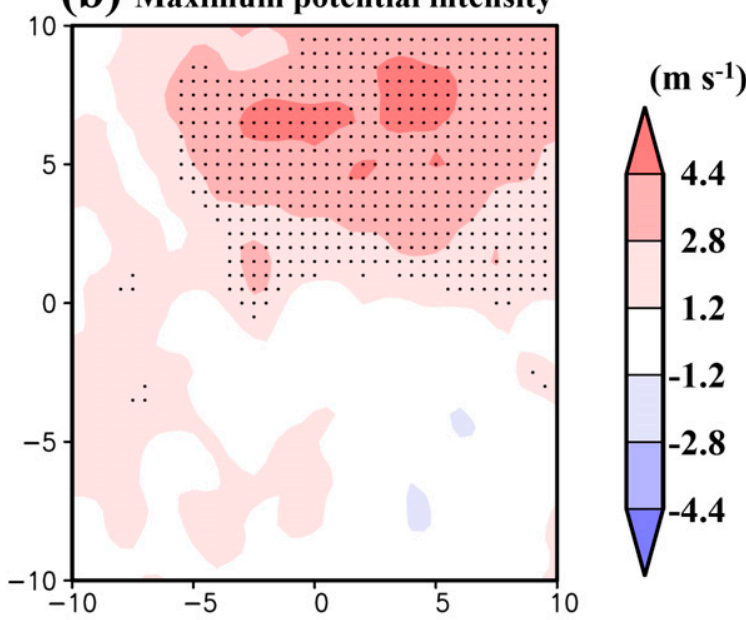

(d) Vertical wind shear

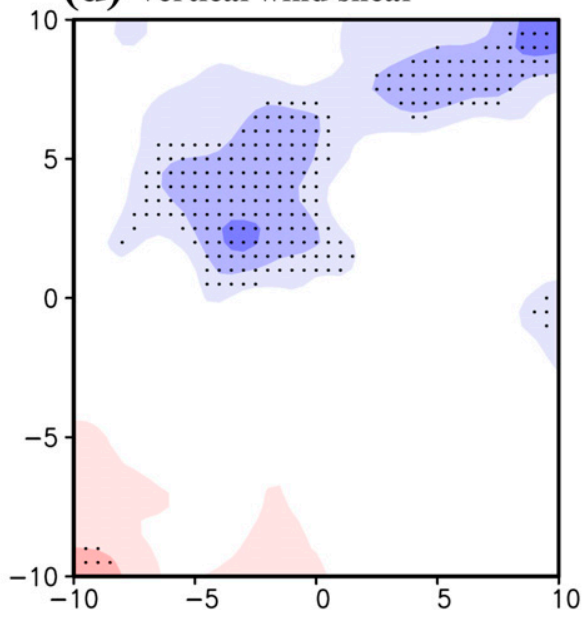

$\left(\mathrm{m} \mathrm{s}^{-1}\right)$

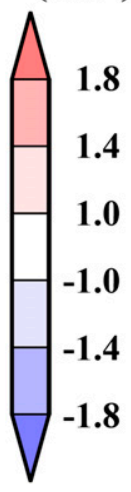

FIG. 14. Differences in (a),(b) maximum potential intensity and (c),(d) 200-850-hPa vertical wind shear between developing and nondeveloping TCCs formed in (left) easterly and (right) monsoon environments over a $20^{\circ} \times 20^{\circ}$ domain centered at the TCC formation location. The black dots indicate the differences that pass the $t$ test at a $95 \%$ confidence level.

respectively), based on the $t$ test with a $95 \%$ confidence level. In other words, the sizes of TCCs and MCSs at the time of TCC formation are not important factors to determine whether the TCC will develop into a TC.
Note that the number of embedded MCSs and their distribution might affect the further development of TCCs associated with different environments and will be analyzed in the future.

TABLE 5. Area-averaged values of four parameters (shown in the first column) inside $5^{\circ}$ radius for developing and nondeveloping TCCs formed in (left) easterly and (right) monsoon environments. Single asterisks $(*)$ indicate that the difference between developing TCCs and nondeveloping TCCs passes the $t$ test at a 95\% confidence level. Plus signs $(+)$ indicate that the difference between developing TCCs formed in easterly and monsoon environments passes the $t$ test at a $95 \%$ confidence level. Hash symbols (\#) indicate that the difference between nondeveloping TCCs formed in easterly and monsoon environments passes the $t$ test at a $95 \%$ confidence level.

\begin{tabular}{|c|c|c|c|c|}
\hline \multirow[b]{2}{*}{ Parameters } & \multicolumn{2}{|c|}{ Easterly } & \multicolumn{2}{|c|}{ Monsoon } \\
\hline & Developing TCC & Nondeveloping TCC & Developing TCC & Nondeveloping TCC \\
\hline $850-\mathrm{hPa}$ relative vorticity $\left(10^{-5} \mathrm{~s}^{-1}\right)$ & $1.26^{+*}$ & $0.73^{\# *}$ & $1.55^{+}$ & $1.69^{\#}$ \\
\hline 600-hPa relative humidity (\%) & $71.3^{+}$ & $72.8^{\#}$ & $76.4^{+}$ & $75.3^{\#}$ \\
\hline Maximum potential intensity $\left(\mathrm{m} \mathrm{s}^{-1}\right)$ & $59.3^{*}$ & $57.9^{*}$ & $59.5^{*}$ & $57.8^{*}$ \\
\hline $200-850-\mathrm{hPa}$ vertical wind shear $\left(\mathrm{m} \mathrm{s}^{-1}\right)$ & $12.5^{+}$ & $12.6^{\#}$ & $14.2^{+}$ & $14.7^{\#}$ \\
\hline
\end{tabular}


Regarding the interannual variations of TCCs, the total number of TCCs in the entire WNP is not sensitive to the ENSO signal, but significant correlations exist between TCC numbers in subregions of the WNP and the ONI (Teng et al. 2014). Note that, because cluster analysis classifies the environments of TCC formations using reanalysis data rather than GridSat, TCC numbers counted in subregions differ slightly from those of Teng et al. (2014). The numbers of TCCs that occur when the WNP circulation is defined by each cluster type are significantly correlated with the ONI, with the exception of type 8 . Because there is no difference in the GPI between El Niño and La Niña years for each cluster type, the difference in TCC number between different ENSO phases is mainly attributed to the frequency change of each environmental pattern rather than a change in the favorable environmental conditions for TCC formation.

Furthermore, the number of TCCs in subregions of the WNP is also significantly influenced by the frequency change of each environmental pattern under the ENSO modulation. Because most TCC formation locations are associated with the extension and retreat of the monsoon confluence and trough, the shift of the monsoon system due to ENSO modulation would redistribute the locations of TCC formations. Therefore, the average location of TCC formations is affected by ENSO, although the total number of TCCs in the entire WNP does not vary significantly with the ENSO signals. This feature is similar to the findings of previous studies (Chen and Weng 1998; Zolman et al. 2000; Wang and Chan 2002; Wu et al. 2012). However, this study shows more clearly the location shift and number change of TCCs that form in each different environment. In addition, the modulation of ENSO on TCC formation in each cluster type deserves further study in the future.

As pointed by previous studies (Ooyama 1982; Lin and Lee 2011; Hsieh et al. 2017), the environmental conditions affect the probability of an initial disturbance to develop into a TC. However, the importance of environmental influences to TC formation appears different for TCCs formed in monsoon and easterly environments. In this study, the GPI is regarded as an objective parameter to assess how favorable the environmental conditions are for TC formation in each cluster type. Analyzing the GPI composite and CDF shows, for TCCs formed in easterly environments, the environmental conditions are more favorable to TC formation for developing TCCs than for nondeveloping TCCs; however, this significant difference does not exist for TCCs formed in monsoon environments. Note that the area-averaged GPIs are similar for developing TCCs formed in monsoon and easterly environments, and the average GPI of nondeveloping TCCs is higher for TCCs formed in monsoon environments than those formed in easterly environments. These results indicate that the probability of the TCC to develop into a TC is sensitive to the environmental conditions in easterly environments, while the environmental conditions at the time of TCC formation are not important to dictate whether the TCC will develop into a TC in monsoon environments. Previous studies showed that the low-level vorticity plays a more important role for TC formation in the WNP than in the North Atlantic (McBride and Zehr 1981; Lee 1989; Fu et al. 2012; Kerns and Chen 2013). In particular, this feature is more obvious for TCCs formed in easterly environments in the WNP according to the results of this study.

In summary, this study not only classifies the environmental circulation patterns associated with TCC formations for a 29-yr period but also objectively quantifies the number, interannual variation, environmental conditions, and statistical features for each cluster type, thereby improving the understanding of TC precursors formed in different environmental patterns. However, TCCs formed in a specific environment can develop into TCs in related or different environments, e.g., a TCC forms in the easterly environment and develops into a TC in the monsoon confluence environment. The dynamic and thermodynamic characteristics may differ when a TCC development crosses different environments. Therefore, clustering the environmental circulation patterns associated with the TCC development into TC deserves further study.

Acknowledgments. Hsu-Feng Teng is supported by the National Taiwan University and the National Center for Atmospheric Research. Cheng-Shang Lee is supported by the National Taiwan University. HuangHsiung Hsu is supported by the Research Center for Environmental Changes of the Academia Sinica and the National Taiwan University. Greg J. Holland and James M. Done are supported by the Willis Research Network and the National Center for Atmospheric Research, which is sponsored by the National Science Foundation. The authors appreciate the help from three anonymous reviewers to significantly improve the manuscript. This research is supported by the Ministry of Science and Technology (MOST) of the Republic of China (Taiwan) under Grants MOST 107-2111-M-002-012, MOST 1072625-M-002-008, and MOST 106-2917-I-564-047 and the National Taiwan University under Grant G1003.

\section{REFERENCES}

Banzon, V., T. M. Smith, T. M. Chin, C. Y. Liu, and W. Hankins, 2016: A long-term record of blended satellite and in situ seasurface temperature for climate monitoring, modeling and environmental studies. Earth Syst. Sci. Data, 8, 165-176, https://doi.org/10.5194/essd-8-165-2016. 
Bessho, K., T. Nakazawa, S. Nishimura, and K. Kato, 2010: Warm core structures in organized cloud clusters developing or not developing into tropical storms observed by the Advanced Microwave Sounding Unit. Mon. Wea. Rev., 138, 2624-2643, https://doi.org/10.1175/2010MWR3073.1.

Bister, M., and K. A. Emanuel, 2002: Low frequency variability of tropical cyclone potential intensity. 1. Interannual to interdecadal variability. J. Geophys. Res., 107, 4801, https://doi.org/ 10.1029/2001JD000776.

Bruyère, C. L., G. J. Holland, and E. Towler, 2012: Investigating the use of a genesis potential index for tropical cyclones in the North Atlantic basin. J. Climate, 25, 8611-8626, https://doi.org/ 10.1175/JCLI-D-11-00619.1.

Camargo, S. J., A. W. Robertson, S. J. Gaffney, and P. Smyth, 2004: Cluster analysis of western North Pacific tropical cyclone tracks. 26th Conf. on Hurricanes and Tropical Meteorology, Miami, FL, Amer. Meteor. Soc., 10A.7, https://ams.confex.com/ ams/pdfpapers/75358.pdf.

_ - K. A. Emanuel, and A. H. Sobel, 2007a: Use of a genesis potential index to diagnose ENSO effects on tropical cyclone genesis. J. Climate, 20, 4819-4834, https://doi.org/10.1175/ JCLI4282.1.

—, A. H. Sobel, A. G. Barnston, and K. A. Emanuel, 2007b: Tropical cyclone genesis potential index in climate models. Tellus, 59A, 428-443, https://doi.org/10.1111/j.1600-0870.2007. 00238.x.

— A. W. Robertson, S. J. Gaffney, P. Smyth, and M. Ghil, 2007c: Cluster analysis of typhoon tracks. Part I: General properties. J. Climate, 20, 3635-3653, https://doi.org/10.1175/JCLI4188.1. ,,,,$---- 2007 \mathrm{~d}$ : Cluster analysis of typhoon tracks. Part II: Large-scale circulation and ENSO. J. Climate, 20, 3654-3676, https://doi.org/10.1175/JCLI4203.1.

Chan, J. C. L., 2000: Tropical cyclone activity over the western North Pacific associated with El Niño and La Niña events. J. Climate, 13, 2960-2972, https://doi.org/10.1175/15200442(2000)013<2960:TCAOTW > 2.0.CO;2.

Chen, D. Y. C., K. K. W. Cheung, and C. S. Lee, 2011: Some implications of core regime wind structures in western North Pacific tropical cyclones. Wea. Forecasting, 26, 61-75, https:// doi.org/10.1175/2010WAF2222420.1.

$[, \ldots$, and $—, 2012$ : A study on the synoptic-dynamical characteristics of compact tropical cyclones in the western North Pacific. Mon. Wea. Rev., 140, 4046-4065, https://doi.org/ 10.1175/MWR-D-11-00317.1.

Chen, J. M., C. H. Wu, P. H. Chung, and C. H. Sui, 2018: Influence of intraseasonal-interannual oscillations on tropical cyclone genesis in the western North Pacific. J. Climate, 31, 4949-4961, https://doi.org/10.1175/JCLI-D-17-0601.1.

Chen, T. C., and S. P. Weng, 1998: Interannual variation of the summer synoptic-scale disturbance activity in the western tropical Pacific. Mon. Wea. Rev., 126, 1725-1733, https://doi.org/ 10.1175/1520-0493(1998)126<1725:IVOTSS > 2.0.CO;2.

Choi, K. S., Y. M. Cha, and T. R. Kim, 2012: Cluster analysis of tropical cyclone tracks around Korea and its climatological properties. Nat. Hazards, 64, 1-18, https://doi.org/10.1007/ s11069-012-0192-7.

Emanuel, K. A., and D. S. Nolan, 2004: Tropical cyclone activity and the global climate. 26th Conf. on Hurricanes and Tropical Meteorology, Miami, FL, Amer. Meteor. Soc., 10A.2, https://ams.confex.com/ams/26HURR/techprogram/ paper_75463.htm.

Everitt, B., S. Landau, M. Leese, and D. Stahl, 2011: Cluster Analysis. 5th ed. John Wiley \& Sons, 346 pp.
Fu, B., M. S. Peng, T. Li, and D. E. Stevens, 2012: Developing versus nondeveloping disturbances for tropical cyclone formation. Part II: Western North Pacific. Mon. Wea. Rev., 140, 1067-1080, https://doi.org/10.1175/2011MWR3618.1.

Garson, G. D., 2014: Cluster Analysis. Statistical Associates Publishers, $207 \mathrm{pp}$.

Gray, W. M., 1998: The formation of tropical cyclones. Meteor. Atmos. Phys., 67, 37-69, https://doi.org/10.1007/BF01277501.

Harr, P. A., and R. L. Elsberry, 1991: Tropical cyclone track characteristics as a function of large-scale circulation anomalies. Mon. Wea. Rev., 119, 1448-1468, https://doi.org/10.1175/ 1520-0493(1991)119<1448:TCTCAA > 2.0.CO;2.

$\longrightarrow$, and —_, 1995a: Large-scale circulation variability over the tropical western North Pacific. Part I: Spatial patterns and tropical cyclone characteristics. Mon. Wea. Rev., 123, 1225-1246, https://doi.org/10.1175/1520-0493(1995)123<1225: LSCVOT>2.0.CO;2.

$\longrightarrow$, and — 1995b: Large-scale circulation variability over the tropical western North Pacific. Part II: Persistence and transition characteristics. Mon. Wea. Rev., 123, 1247-1268, https://doi.org/ 10.1175/1520-0493(1995)123<1247:LSCVOT > 2.0.CO;2

Hennon, C. C., C. N. Helms, K. R. Knapp, and A. R. Bowen, 2011: An objective algorithm for detecting and tracking tropical cloud clusters: Implications for tropical cyclogenesis prediction. J. Atmos. Oceanic Technol., 28, 1007-1018, https:// doi.org/10.1175/2010JTECHA1522.1.

- , and Coauthors, 2013: Tropical cloud cluster climatology, variability, and genesis productivity. J. Climate, 26, 3046-3066, https://doi.org/10.1175/JCLI-D-12-00387.1.

Hill, K. A., and G. M. Lackmann, 2009: Influence of environmental humidity on tropical cyclone size. Mon. Wea. Rev., 137, 3294 3315, https://doi.org/10.1175/2009MWR2679.1.

Hsieh, Y. H., C. S. Lee, and C. H. Sui, 2017: A study on the influences of low-frequency vorticity on tropical cyclone formation in the western North Pacific. Mon. Wea. Rev., 145, 4151-4169, https://doi.org/10.1175/MWR-D-17-0085.1.

Kerns, B. W., and S. Y. S. Chen, 2013: Cloud clusters and tropical cyclogenesis: Developing and nondeveloping systems and their large-scale environment. Mon. Wea. Rev., 141, 192-210, https://doi.org/10.1175/MWR-D-11-00239.1.

, and _ 2015: Subsidence warming as an underappreciated ingredient in tropical cyclogenesis. Part I: Aircraft observations. J. Atmos. Sci., 72, 4237-4260, https://doi.org/10.1175/ JAS-D-14-0366.1.

Kim, H. K., and K. H. Seo, 2016: Cluster analysis of tropical cyclone tracks over the western North Pacific using a self-organizing map. J. Climate, 29, 3731-3751, https://doi.org/10.1175/JCLID-15-0380.1.

Kim, H. S., J. H. Kim, C. H. Ho, and P. S. Chu, 2011: Pattern classification of typhoon tracks using the fuzzy C-means clustering method. J. Climate, 24, 488-508, https://doi.org/ 10.1175/2010JCLI3751.1.

Knapp, K. R., 2008: Scientific data stewardship of International Satellite Cloud Climatology Project B1 global geostationary observations. J. Appl. Remote Sens., 2, 023548, https://doi.org/ 10.1117/1.3043461.

- and Coauthors, 2011: Globally gridded satellite (GridSat) observations for climate studies. Bull. Amer. Meteor. Soc., 92, 893-907, https://doi.org/10.1175/2011BAMS3039.1.

Leary, C. A., and R. A. Houze, 1976: Analysis of gate radar data for a tropical cloud cluster in an easterly wave. Preprints, 17 th Conf. on Radar Meteorology, Seattle, WA, Amer. Meteor. Soc., 373-383. 
, and - 1979: Structure and evolution of convection in a tropical cloud cluster. J. Atmos. Sci., 36, 437-457, https://doi.org/ 10.1175/1520-0469(1979)036<0437:TSAEOC $>2.0$. CO;2.

Lee, C. S., 1989: Observational analysis of tropical cyclogenesis in the western North Pacific. Part I: Structural evolution of cloud clusters. J. Atmos. Sci., 46, 2580-2598, https://doi.org/10.1175/ 1520-0469(1989)046<2580:OAOTCI >2.0.CO;2.

— K. K. W. Cheung, J. S. N. Hui, R. L. Elsberry, 2008: Mesoscale features associated with tropical cyclone formations in the western North Pacific. Mon. Wea. Rev., 136, 2006-2022, https://doi.org/10.1175/2007MWR2267.1.

$\longrightarrow,-$, W. T. Fang, and R. L. Elsberry, 2010: Initial maintenance of tropical cyclone size in the western North Pacific. Mon. Wea. Rev., 138, 3207-3223, https://doi.org/10.1175/2010MWR3023.1.

Lin, Y. L., and C. S. Lee, 2011: An analysis of tropical cyclone formations in the South China Sea during the late season. Mon. Wea. Rev., 139, 2748-2760, https://doi.org/10.1175/2011MWR3495.1.

Liu, K. S., and J. C. L. Chan, 2002: Synoptic flow patterns associated with small and large tropical cyclones over the western North Pacific. Mon. Wea. Rev., 130, 2134-2142, https://doi.org/ 10.1175/1520-0493(2002)130<2134:SFPAWS > 2.0.CO;2.

Machado, L. A. T., and W. B. Rossow, 1993: Structural characteristics and radiative properties of tropical cloud clusters. Mon. Wea. Rev., 121, 3234-3260, https://doi.org/10.1175/15200493(1993) $121<3234:$ SCARPO $>2.0$.CO;2.

_ J. P. Duvel, and M. Desbois, 1993: Diurnal variations and modulation by easterly waves of the size distribution of convective cloud clusters over West Africa and the Atlantic Ocean. Mon. Wea. Rev., 121, 37-49, https://doi.org/10.1175/ 1520-0493(1993)121<0037:DVAMBE >2.0.CO;2.

MacQueen, J., 1967: Some methods for classification and analysis of multivariate observations. Proc. Fifth Berkeley Symp. on Mathematical Statistics and Probability, Berkeley, CA, University of California, 281-297.

Mapes, B. E., and R. A. Houze, 1993: Cloud clusters and superclusters over the oceanic warm pool. Mon. Wea. Rev., 121, 1398-1415, https://doi.org/10.1175/1520-0493(1993)121<1398: CCASOT $>2.0 . \mathrm{CO} ; 2$.

McBride, J. L., 1981: Observational analysis of tropical cyclone formation. Part I: Basic description of data sets. J. Atmos. Sci., 38, 1117-1131, https://doi.org/10.1175/1520-0469(1981)038<1117: OAOTCF $>2.0 . \mathrm{CO} ; 2$.

_- and R. Zehr, 1981: Observational analysis of tropical cyclone formation. Part II: Comparison of non-developing versus developing systems. J. Atmos. Sci., 38, 1132-115, https://doi.org/ 10.1175/1520-0469(1981)038<1132:OAOTCF $>2.0$. CO;2.

Murakami, H., G. Villarini, G. A. Vecchi, W. Zhang, and R. Gudgel, 2016: Statistical-dynamical seasonal forecast of North Atlantic and U.S. landfalling tropical cyclones using the high-resolution GFDL FLOR coupled model. Mon. Wea. Rev., 144, 2101-2123, https://doi.org/10.1175/MWR-D-15-0308.1.

Ooyama, K. V., 1982: Conceptual evolution of the theory and modeling of the tropical cyclone. J. Meteor. Soc. Japan, 60, 369-380, https://doi.org/10.2151/jmsj1965.60.1_369.

Ramsay, H. A., S. J. Camargo, and D. Kim, 2012: Cluster analysis of tropical cyclone tracks in the Southern Hemisphere. Climate Dyn., 39, 897-917, https://doi.org/10.1007/s00382-011-1225-8.

Reynolds, R. W., T. M. Smith, C. Liu, D. B. Chelton, K. S. Casey, and M. G. Schlax, 2007: Daily high-resolution-blended analyses for sea surface temperature. J. Climate, 20, 54735496, https://doi.org/10.1175/2007JCLI1824.1.

Saha, S., and Coauthors, 2010: The NCEP Climate Forecast System Reanalysis. Bull. Amer. Meteor. Soc., 91, 1015-1057, https:// doi.org/10.1175/2010BAMS3001.1.

Satoh, M., R. Nihonmatsu, and H. Kubokawa, 2013: Environmental conditions for tropical cyclogenesis associated with African easterly waves. SOLA, 9, 120-124, https://doi.org/ 10.2151/sola.2013-027.

Teng, H. F., 2016: Formation and development of tropical cloud cluster in the western North Pacific. Ph.D. thesis, National Taiwan University, $178 \mathrm{pp}$.

— C. S. Lee, and H. H. Hsu, 2014: Influence of ENSO on formation of tropical cloud clusters and their development into tropical cyclones in the western North Pacific. Geophys. Res. Lett., 41, 9120-9126, https://doi.org/10.1002/2014GL061823.

Trenberth, K. E., 1997: The definition of El Niño. Bull. Amer. Meteor. Soc., 78, 2771-2777, https://doi.org/10.1175/15200477(1997)078<2771:TDOENO > 2.0.CO;2.

Wang, B., and J. C. L. Chan, 2002: How strong ENSO events affect tropical storm activity over the western North Pacific. J. Climate, 15, 1643-1658, https://doi.org/10.1175/1520-0442(2002)015<1643: HSEEAT $>2.0 . \mathrm{CO} ; 2$.

_ R. G. Wu, and K. M. Lau, 2001: Interannual variability of the Asian summer monsoon: Contrasts between the Indian and the western North Pacific-east Asian monsoons. J. Climate, 14, 4073-4090, https://doi.org/10.1175/1520-0442(2001)014<4073: IVOTAS $>2.0 . \mathrm{CO} ; 2$.

Wang, J. J., X. F. Li, and L. D. Carey, 2007: Evolution, structure, cloud microphysical, and surface rainfall processes of monsoon convection during the South China Sea monsoon experiment. J. Atmos. Sci., 64, 360-380, https://doi.org/10.1175/ JAS3852.1.

Williams, M., and R. A. Houze, 1987: Satellite-observed characteristics of winter monsoon cloud clusters. Mon. Wea. Rev., 115, 505-519, https://doi.org/10.1175/1520-0493(1987) $115<0505$ :SOCOWM $>2.0 . \mathrm{CO} ; 2$.

Wu, L. G., Z. P. Wen, R. H. Huang, and R. G. Wu, 2012: Possible linkage between the monsoon trough variability and the tropical cyclone activity over the western North Pacific. Mon. Wea. Rev., 140, 140-150, https://doi.org/10.1175/MWR-D-11-00078.1.

Yoshida, R., and H. Ishikawa, 2013: Environmental factors contributing to tropical cyclone genesis over the western North Pacific. Mon. Wea. Rev., 141, 451-467, https://doi.org/10.1175/ MWR-D-11-00309.1.

Zhao, H. K., R. Yoshida, and G. B. Raga, 2015: Impact of the Madden-Julian oscillation on western North Pacific tropical cyclogenesis associated with large-scale patterns. J. Appl. Meteor. Climatol., 54, 1413-1429, https://doi.org/10.1175/ JAMC-D-14-0254.1.

_ S. H. Chen, P. J. Klotzbach, and G. B. Raga, 2018: Impact of the extended boreal summer intraseasonal oscillation on western North Pacific tropical cloud cluster genesis productivity. J. Climate, 31, 9175-9191, https://doi.org/10.1175/ JCLI-D-18-0113.1.

Zolman, J. L., E. J. Zipser, and K. I. Mohr, 2000: A comparison of tropical mesoscale convective systems in El Niño and La Niña. J. Climate, 13, 3314-3326, https://doi.org/10.1175/15200442(2000)013<3314:ACOTMC > 2.0.CO;2. 